\title{
What do Latin American inflation targeters care about? A comparative Bayesian estimation of Central Bank preferences
}

Article

Accepted Version

Creative Commons: Attribution-Noncommercial-No Derivative Works 4.0

McKnight, S., Mihailov, A. and Pompa Rangel, A. (2020) What do Latin American inflation targeters care about? A comparative Bayesian estimation of Central Bank preferences. Journal of Macroeconomics, 63. 103188. ISSN 0164-0704 doi: https://doi.org/10.1016/j.jmacro.2019.103188 Available at https://centaur.reading.ac.uk/88052/

It is advisable to refer to the publisher's version if you intend to cite from the work. See Guidance on citing.

To link to this article DOI: http://dx.doi.org/10.1016/j.jmacro.2019.103188

Publisher: Elsevier

All outputs in CentAUR are protected by Intellectual Property Rights law, including copyright law. Copyright and IPR is retained by the creators or other copyright holders. Terms and conditions for use of this material are defined in the End User Agreement.

www.reading.ac.uk/centaur 
Central Archive at the University of Reading

Reading's research outputs online 


\title{
What Do Latin American Inflation Targeters Care About? A Comparative Bayesian Estimation of Central Bank Preferences
}

\author{
Stephen McKnight* $\quad$ Alexander Mihailov ${ }^{\dagger}$ \\ Antonio Pompa Rangel ${ }^{\ddagger}$
}

Accepted, in this 3rd (minor editorial) revision, Journal of Macroeconomics: 18 December 2019

${ }^{*}$ Centro de Estudios Económicos, El Colegio de México, Camino al Ajusco 20, Col. Pedregal de Santa Teresa, Mexico City, 10740, Mexico. E-mail: mcknight@colmex.mx

${ }^{\dagger}$ Corresponding author: Department of Economics, University of Reading, Whiteknights, PO Box 218, Reading, RG6 6AA, United Kingdom. E-mail: a.mihailov@reading.ac.uk

‡Dirección General de Investigación Económica, Banco de México, Calle 5 de Mayo 18, Col. Centro, Mexico City, 06069, Mexico. E-mail: antonio.pompa@banxico.org.mx 


\begin{abstract}
This paper employs Bayesian estimation to uncover the central bank preferences of the five Latin American inflation targeting countries with floating exchange rates: Brazil, Chile, Colombia, Mexico, and Peru. The target weights of each country's central bank loss function are estimated using a medium-scale small open economy New Keynesian model with imperfect exchange-rate pass-through under either complete or incomplete international asset markets. Bayesian model comparison selects: (i) unambiguously the complete markets model version; (ii) the model specification with explicit concern for real exchange rate stabilization, with the exception of Peru. Our results suggest that the central banks of Mexico and Peru are closest to following a strict inflation targeting regime, whereas Brazil, Chile, and Colombia also assign a sizeable weight to output gap and real exchange rate stabilization. Finally, the estimated preference weights for each central bank are shown to credibly reflect their legal mandates.
\end{abstract}

JEL codes: C51, E52, F41.

Keywords: Bayesian model comparison; international asset market structure; central bank preferences; inflation targeting; Latin America; small open economies; monetary policy. 


\section{Introduction}

For many central banks in both developed and developing countries, inflation targeting (IT) has become the operational monetary framework of choice to achieve price stability. ${ }^{1}$ According to the International Monetary Fund (IMF) (see, e.g., Jahan, 2012), since the adoption of IT by New Zealand in December 1989, there are now 28 IT central banks worldwide, of which 6 currently originate from Latin America: Brazil, Chile, and Colombia all adopted IT in 1999, shortly followed by Mexico (2001), Peru (2002), and Guatemala (2005) (see Table 1). ${ }^{2}$ While there is some empirical evidence to suggest that IT has been successful in reducing inflation in developing countries (see, e.g., Batini and Laxton, 2007; Goncalves and Salles, 2008; Lin and Ye, 2009; Lee, 2011), ${ }^{3}$ little is known about the policy preferences of central banks operating in these countries. ${ }^{4}$ As discussed by Castelnuovo and Surico (2004) and Ilbas (2010, 2012), such information can help in evaluating the performance of central banks, as well as improving our understanding of monetary policy actions and its effects on the formation of expectations by private agents.

The aim of this paper is to use Bayesian estimation techniques to uncover and compare the central bank preferences of the five Latin American inflation targeting (LAIT) countries operating under a floating exchangerate regime. ${ }^{5}$ Since the IT framework can be considered as "constrained discretion" (Bernanke and Mishkin, 1997), we assume that in each country monetary policy is conducted under optimal discretion (Dennis, 2007). Each central bank is assumed to optimally set the nominal interest rate by

\footnotetext{
${ }^{1}$ See, e.g., Mishkin and Schmidt-Hebbel (2001), Carare and Stone (2006), Roger (2010), Hammond (2011), Jahan (2012).

${ }^{2}$ As Table 1 reveals, there is significant heterogeneity across these 6 Latin American countries in terms of the inflation target set and their performance in steering actual inflation towards the target.

${ }^{3}$ Lee (2011) finds that IT has been particularly successful in reducing inflation in Colombia, while no significant reductions were found for Chile. In contrast to much of the earlier literature, Brito and Bystedt (2010) find no evidence that IT improves economic performance in developing countries, as measured by the behavior of inflation and output growth.

${ }^{4}$ There is also some evidence to suggest that IT has reduced the dispersion of longrun inflation expectations in developing countries. See Capistrán and Ramos-Francia (2010) for further details.

${ }^{5}$ We exclude Guatemala from the analysis because its exchange-rate regime is defined by the IMF as a "stabilized arrangement" - see Table 1.
} 
minimizing a quadratic loss function that includes four specific policy objectives: price stability via control of inflation, stabilizing the output gap, reducing real exchange rate variability, and nominal interest rate smoothing. The weight attributed to each policy objective will depend on the institutional preferences of each central bank, which we can make inferences about using estimates of the respective Bayesian posterior distributions.

The structural model used to represent the LAIT economies is a dynamic medium-scale small open economy New Keynesian model. Following the modeling frameworks of Monacelli (2005), Kam et al. (2009), and Justiniano and Preston (2010), we allow for imperfect exchange-rate passthrough (ERPT) such that the law of one price fails to hold. However, in similar set-ups the literature has assumed that international asset markets are either complete, e.g., as in Galí and Monacelli (2005), Monacelli (2005), and Kam et al. (2009), or incomplete, e.g., as in Adolfson et al. (2007) and Justiniano and Preston (2010). Instead, we consider both international asset market structures and use the Bayes factor to compare between them. ${ }^{6}$ Using the popular Random-Walk Metropolis-Hastings Markov Chain Monte Carlo algorithm, we present posterior estimates and convergence diagnostics for both the structural parameters and the persistence and standard deviations of the shocks we consider as most important for the LAIT economies, including cost-push shocks to the prices of imported and domestic goods, and shocks to the risk premium, the terms of trade, and technology.

Our main findings are as follows. First, we find that for the LAITs in our sample the assumption of complete asset markets is unambiguously preferred to the alternative of incomplete asset markets, as commonly but simplistically modeled by a riskless bond-only financial system. The superiority of the marginal likelihoods under complete asset markets is always sufficiently large to suggest strong statistical evidence in favor of complete markets over the incomplete asset markets version.

Second, all five central banks are strongly concerned about stabilizing inflation and smoothing the nominal interest rate. In particular, relative to

\footnotetext{
${ }^{6}$ Rabanal and Tuesta (2010) perform a similar Bayesian model comparison in a twocountry open-economy model framework estimated for the United States and the Euro Area.
} 
the weight of inflation stabilization, we find that Chile and Peru place very high weights on interest rate smoothing. Third, there is significant heterogeneity amongst the five central banks concerning the target weights of output gap stabilization and real exchange rate stabilization. Our analysis suggests that Mexico and Peru show little concern for the stabilization of the output gap, whereas Brazil, Chile, and Colombia assign sizable weights. While all the LAIT central banks except that of Peru are concerned about real exchange rate stabilization, only Brazil and Chile are found to assign a sizable weight to minimizing real exchange rate fluctuations.

Overall, Peru and, less so, Mexico show evidence of implementing a strict inflation targeting regime, whereas Brazil, Chile, and Colombia appear much more flexible in terms of their macroeconomic policy objectives. Our estimated preference weights for the four policy objectives are shown to be broadly consistent with regard to the respective legal mandates of the five LAIT central banks.

In terms of the estimated key structural parameters influencing the endogenous propagation mechanism of the model, we find that these are statistically reliable, economically plausible, and broadly comparable to analogous estimates for other countries available in the literature using non-Bayesian econometric methods. For example, the estimated elasticity of substitution between home and foreign goods is within the typical range reported in Corsetti et al. (2008). Further, the estimated inverse Frisch elasticity of labor supply is also clustered tightly for all five LAITs in a typical range for other economies. With the exception of Chile, our estimates also reveal lower habit persistence than that for advanced economies, including those reported by Kam et al. (2009).

In terms of the sources of exogenous fluctuations affecting the five LAIT economies, our results indicate a high relative volatility (measured by the posterior mean standard deviation) for cost-push shocks to both imported and domestic goods, terms of trade shocks and, less so, productivity shocks, dominating in most of the LAIT economies. For four of our five LAIT economies, risk premium shocks are estimated to be the most persistent, whereas terms of trade shocks are estimated to be the least persistent. 
There are few papers that have used Bayesian techniques to estimate central bank preferences in an open-economy setting. ${ }^{7}$ Lubik and Schorfheide (2007) find, examining four advanced IT economies, that the central banks of Canada and the UK react to the nominal exchange rate in the monetary policy rule, whereas the central banks of Australia and New Zealand do not. Kam et al. (2009) estimate the central bank preferences for three developed IT countries, Australia, Canada, and New Zealand under optimal discretionary monetary policy. They find that the central banks of these countries all have very similar preferences: the highest priority is inflation stabilization, followed by interest rate smoothing, with no concern for stabilizing the output gap (with the exception of Australia) and the real exchange rate. Palma and Portugal (2014) estimate the model of Kam et al. (2009) using Brazilian data. They find that the major concern of the central bank of Brazil is inflation stabilization, followed by interest rate smoothing, real exchange rate stabilization, and output gap stabilization. While the estimation approach adopted in this paper is similar to Kam et al. (2009), who assume complete asset markets, we additionally examine the model fit of incomplete asset markets. Moreover, Rabanal and Tuesta (2010) show that the extent of international financial market integration affects both the Bayesian estimates of the parameters and the transmission mechanism of shocks. Our analysis emphasizes the implications for Bayesian estimation of using different international asset markets assumptions in fitting the data, particularly when uncovering central bank preferences.

The paper is organized as follows. Section 2 outlines the theoretical model. Section 3 describes the data and explains the estimation strategy. Section 4 reports our main results. Finally, section 5 concludes.

\section{The Model}

This section outlines the model economy, which is based on the small open economy frameworks of Monacelli (2005), Kam et al. (2009), and

\footnotetext{
${ }^{7}$ In a closed-economy setting, Ilbas $(2010,2012)$ estimates the preferences of the European Central Bank and the US Federal Reserve, respectively, under commitment using the structural models of Smets and Wouters (2003, 2007).
} 
Justiniano and Preston (2010). The domestic economy is populated by infinitely-lived households of measure one, a continuum of domestic good producers, a continuum of retail firms who import foreign goods at competitive world prices, and a central bank. Both domestic-goods producing and foreign-goods importing retail firms are assumed to operate under monopolistic competition and set prices in a staggered fashion according to Calvo (1983). Market power in the retail sector for imported goods results in incomplete ERPT and thus the law of one price fails to hold. We consider two alternative model structures where international financial markets are either assumed to be complete, as in Galí and Monacelli (2005), Monacelli (2005), and Kam et al. (2009), denoted as CAM henceforth, or incomplete, as in Adolfson et al. (2007) and Justiniano and Preston (2010), denoted as IAM. Following Dennis (2007) and Kam et al. (2009), the inflationtargeting central bank is assumed to minimize a quadratic loss function under discretion. In what follows, asterisks conventionally denote foreign variables, and subscripts $H(F)$ denote variables of Home (Foreign) origin.

\subsection{Households}

Households consume a composite of domestic $C_{H}$ and imported $C_{F}$ goods:

$$
\begin{gathered}
C_{t}=\left[(1-\alpha)^{\frac{1}{n}} C_{H, t}^{\frac{\eta-1}{\eta}}+\alpha^{\frac{1}{n}} C_{F, t}^{\frac{\eta-1}{\eta}}\right], \\
C_{H, t}=\left[\int_{0}^{1} C_{H, t}(i)^{\frac{\varepsilon-1}{\varepsilon}} d i\right]^{\frac{\varepsilon}{\varepsilon-1}} ; \quad C_{F, t}=\left[\int_{0}^{1} C_{F, t}(j)^{\frac{\varepsilon-1}{\varepsilon}} d j\right]^{\frac{\varepsilon}{\varepsilon-1}} .
\end{gathered}
$$

The parameter $\eta>0$ measures the elasticity of substitution between home and foreign goods, $\alpha \in(0,1)$ is the share of foreign goods in the domestic consumption bundle, and $\varepsilon>1$ measures the elasticity of substitution between the varieties of goods produced within $H$ or $F$, where $i, j \in[0,1]$. The optimal allocation of expenditures between domestic and imported goods yields the following aggregate demand conditions:

$$
C_{H, t}=(1-\alpha)\left(\frac{P_{H, t}}{P_{t}}\right)^{-\eta} C_{t}, \quad C_{F, t}=\alpha\left(\frac{P_{F, t}}{P_{t}}\right)^{-\eta} C_{t}
$$


where the consumer price index $P_{t}$ is given by:

$$
P_{t}=\left[(1-\alpha) P_{H, t}^{1-\eta}+\alpha P_{F, t}^{1-\eta}\right]^{\frac{1}{1-\eta}} .
$$

The (home) real exchange rate $\tilde{q}_{t}$ is defined by:

$$
\tilde{q}_{t}=\tilde{e}_{t} \frac{P_{t}^{*}}{P_{t}}
$$

where $\tilde{e}_{t}$ denotes the (home) nominal exchange rate. The relative price of foreign goods in terms of home goods, or the (home) terms of trade, $S_{t}$, is expressed as:

$$
S_{t}=\frac{P_{F, t}}{P_{H, t}}
$$

The representative household chooses consumption $C_{t}$ and labor $N_{t}$ to maximize expected discounted utility:

$$
\max \mathbb{E}_{0} \sum_{t=0}^{\infty} \beta U\left(\frac{\left(C_{t}-H_{t}\right)^{1-\sigma}}{1-\sigma}-\frac{N_{t}^{1+\varphi}}{1+\varphi}\right),
$$

where the discount factor is $\beta \in(0,1), \sigma, \varphi>0$ are the inverse elasticities of intertemporal substitution and labor supply, respectively, $H_{t} \equiv h C_{t-1}$ is an external habit variable with $h \in(0,1)$. The household during period $t$ supplies labor (hours) $N_{t}$ to domestic firms receiving income from wages $W_{t}$ and profits from the ownership of domestic and retail firms $\Pi_{t}$.

In what follows we consider alternative model versions depending on whether international financial markets are assumed to be complete or incomplete. Under incomplete asset markets, let $B_{t-1}$ and $B_{t-1}^{*}$ denote the holdings of home and foreign risk-free bonds that mature in period $t$ with corresponding interest rates $\widetilde{r}_{t}$ and $\widetilde{r}_{t}^{*}$. Following Kollmann (2002), Schmitt-Grohé and Uribe (2003), Benigno (2009), and Justiniano and Preston (2010), we assume that there is a debt-elastic interest rate premium $\omega_{t-1}\left(D_{t-1}, \epsilon_{q, t-1}\right)$ given by:

$$
\omega_{t-1}=\exp \left[-\chi\left(D_{t-1}+\epsilon_{q, t-1}\right)\right], \quad D_{t-1} \equiv \frac{\tilde{e}_{t-1} B_{t-1}^{*}}{Y_{s s} P_{t-1}}
$$


where $\epsilon_{q, t-1}$ is a risk premium shock and $D_{t-1}$ is defined as the ratio of the real quantity of foreign bond holdings (expressed in terms of domestic currency) to steady state output $Y_{s s}$. If the household is a borrower $\left(D_{t}>0\right)$, it must pay a premium over the interest rate. The chosen functional form for the debt-elastic interest rate premium is sufficient to ensure that bond holdings are stationary in a log-linear approximation to the model. ${ }^{8}$ Alternatively, Alonso-Carrera and Kam (2016) close their incomplete markets model by endogenizing the discount factor $\beta$. One advantage of their approach is that it does not require a specific law of motion for foreign bond holdings, thus avoiding the introduction of an additional state variable into the analysis. We favor a debt-elastic interest rate premium to induce stationarity as there is empirical evidence for emerging economies supporting a debt-sensitive interest rate (see, for example, Uribe and Yue, 2006).

The period budget constraint of the domestic household under IAM can be expressed as:

$P_{t} C_{t}+B_{t}+\tilde{e}_{t} B_{t}^{*}=B_{t-1}\left(1+\widetilde{r}_{t-1}\right)+\tilde{e}_{t} B_{t-1}^{*}\left(1+\widetilde{r}_{t-1}^{*}\right) \omega_{t-1}\left(D_{t-1}, \epsilon_{q, t-1}\right)+W_{t} N_{t}+\Pi_{t}$.

The first-order conditions from the households maximization problem under IAM yield:

$$
\begin{gathered}
\left(C_{t}-H_{t}\right)^{\sigma} N_{t}^{\varphi}=\frac{W_{t}}{P_{t}} \\
\beta\left(1+\widetilde{r}_{t}\right) \mathbb{E}_{t}\left\{\left(\frac{C_{t+1}-H_{t+1}}{C_{t}-H_{t}}\right)^{-\sigma}\left(\frac{P_{t}}{P_{t+1}}\right)\right\}=1 \\
\mathbb{E}_{t}\left\{\frac{\left(C_{t+1}-H_{t+1}\right)^{-\sigma}}{P_{t+1}}\left[\left(1+\widetilde{r}_{t}\right)-\left(1+\widetilde{r}_{t}^{*}\right)\left(\frac{\tilde{e}_{t+1}}{\tilde{e}_{t}}\right) \omega_{t}\left(D_{t}, \epsilon_{q, t}\right)\right]\right\}=0 .
\end{gathered}
$$

Equation (9) is the intratemporal labor supply condition, (10) is the intertemporal consumption Euler equation, and (11) is the interest rate parity condition.

\footnotetext{
${ }^{8}$ For an in-depth discussion of the stationarity problem of small open-economy models with incomplete asset markets, see Schmitt-Grohé and Uribe (2003).
} 
Under the alternative assumption of CAM and given identical global preferences, eq. (11) is replaced by:

$$
\left(\frac{C_{t+1}-H_{t+1}}{C_{t}-H_{t}}\right)^{-\sigma} \frac{P_{t}}{P_{t+1}}=\left(\frac{C_{t+1}^{*}-H_{t+1}^{*}}{C_{t}^{*}-H_{t}^{*}}\right)^{-\sigma} \frac{P_{t}^{*}}{P_{t+1}^{*}} \frac{\tilde{e}_{t}}{\tilde{e}_{t+1}}
$$

so that perfect risk sharing obtains (from the analogous first-order conditions in the rest of the world) for all dates and states. Rearranging eq. (12) yields:

$$
\frac{\left(\frac{C_{t+1}^{*}-H_{t+1}^{*}}{C_{t}^{*}-H_{t}^{*}}\right)^{-\sigma}}{\left(\frac{C_{t+1}-H_{t+1}}{C_{t}-H_{t}}\right)^{-\sigma}}=\frac{\frac{P_{t+1}^{*} \tilde{e}_{t+1}}{P_{t+1}}}{\frac{P_{t}^{*} \tilde{e}_{t}}{P_{t}}}=\frac{\widetilde{q}_{t+1}}{\widetilde{q}_{t}} .
$$

Equation (13) shows that under CAM real exchange rate growth equals the marginal rate of substitution in consumption growth across countries. ${ }^{9}$

The key difference between the two financial market structures is that complete asset markets implies perfect risk sharing. Incomplete asset markets breaks this link (see Chari et al., 2002, and Rabanal and Tuesta, 2010). Moreover, as shown by Alonso-Carrera and Kam (2016), under imperfect international risk sharing there is an explicit real exchange-rate channel that can exacerbate the domestic inflation to output gap trade-off.

\subsection{Domestic Good Producers}

The domestic goods market is comprised of a continuum of monopolistically competitive firms $i \in[0,1]$ that produce differentiated goods. Domestic firms hire labor $N$ to produce output using a linear production technology:

$$
Y_{H, t}(i)=\epsilon_{a, t} N_{t}(i)
$$

where $\epsilon_{a, t}$ is an exogenous domestic technology shock, and given competitive prices of labor, cost minimization yields:

$$
M C_{t}=\frac{W_{t}}{\epsilon_{a, t} P_{H, t}}
$$

where $M C_{t}$ denotes real marginal cost.

\footnotetext{
${ }^{9}$ For more details, see, e.g., Monacelli (2005) and Kam et al. (2009).
} 
Domestic firms set prices according to Calvo (1983), where in each period there is a constant probability $1-\theta_{H}$ that a firm will be randomly selected to adjust its price, while a fraction $0<\theta_{H}<1$ adjusts their prices according to the following indexation rule:

$$
P_{H, t}(i)=P_{H, t-1}(i)\left(\frac{P_{H, t-1}}{P_{H, t-2}}\right)^{\delta_{H}}
$$

where $\delta_{H} \in[0,1]$ measures the degree of inflation indexation. For simplicity, we assume that the export price of the domestic good is determined by the law of one price: $P_{H_{t}}^{*}=\left(1 / S_{t}\right) P_{H, t}$. A domestic firm $i$, faced with changing its price at time $t$, has to choose $P_{H, t}(i)$ to maximize its expected discounted value of profits:

$\max _{P_{H, t}(i)} \mathbb{E}_{t} \sum_{s=0}^{\infty} Q_{t, t+s} \theta_{H}^{s}\left[P_{H, t}(i)\left(\frac{P_{H, t+s-1}}{P_{H, t-1}}\right)^{\delta_{H}}-P_{H, t+s} M C_{t+s} \exp \left(\epsilon_{H, t+s}\right)\right] Y_{H, t+s}(i)$,

where

$$
Y_{H, t+s}(i)=\left(\frac{P_{H, t}(i)}{P_{H, t+s}}\left(\frac{P_{H, t+s-1}}{P_{H, t-1}}\right)^{\delta_{H}}\right)^{-\varepsilon}\left(C_{H, t+s}+C_{H, t+s}^{*}\right)
$$

and $\epsilon_{H, t}$ is a cost-push shock. The first-order condition is:

$\mathbb{E}_{t} \sum_{s=0}^{\infty} Q_{t, t+s} \theta_{H}^{s} Y_{H, t+s}(i)\left[\tilde{P}_{H, t}\left(\frac{P_{H, t+s-1}}{P_{H, t-1}}\right)^{\delta_{H}}-\left(\frac{\varepsilon}{\varepsilon-1}\right) P_{H, t+s} M C_{t+s} \exp \left(\epsilon_{H, t+s}\right)\right]=0$

The aggregate price level evolves according to:

$$
P_{H, t}=\left[\left(1-\theta_{H}\right)\left(\tilde{P}_{H, t}\right)^{1-\varepsilon}+\theta_{H}\left(P_{H, t-1}\left(\frac{P_{H, t-1}}{P_{H, t-2}}\right)^{\delta_{H}}\right)^{1-\varepsilon}\right]^{\frac{1}{1-\varepsilon}}
$$

\subsection{Retail Firms}

The retail market is comprised of a continuum of monopolistically competitive firms $j \in[0,1]$ that import differentiated goods from abroad. Similar to domestic firms, retail firms also set prices according to Calvo (1983) where in each period there is a constant probability $1-\theta_{F}$ that a retail 
firm will be randomly selected to adjust its price. ${ }^{10}$ Faced with changing its price at time $t$, a retail firm $j$ importing a good at $\operatorname{cost} \tilde{e}_{t} P_{F, t}^{*}(j)$ chooses $P_{F, t}(j)$ to maximize its expected discounted value of profits:

$\max _{P_{F, t}(j)} \mathbb{E}_{t} \sum_{s=0}^{\infty} Q_{t, t+s} \theta_{F}^{s}\left[P_{F, t}(j)\left(\frac{P_{F, t+s-1}}{P_{F, t-1}}\right)^{\delta_{F}}-\tilde{e}_{t+s} P_{F, t+s}^{*}(j) \exp \left(\epsilon_{F, t+s}\right)\right] Y_{F, t+s}(j)$,

where

$$
Y_{F, t+s}(j)=\left[\frac{P_{F, t}(j)}{P_{F, t+s}}\left(\frac{P_{F, t+s-1}}{P_{F, t-1}}\right)^{\delta_{F}}\right]^{-\varepsilon} C_{F, t+s}
$$

and $\epsilon_{F, t}$ is a cost-push shock to import retailers. The first-order condition is given by:

$\mathbb{E}_{t} \sum_{s=0}^{\infty} Q_{t, t+s} \theta_{F}^{s} Y_{F, t+s}(j)\left[\tilde{P}_{F, t}\left(\frac{P_{F, t+s-1}}{P_{F, t-1}}\right)^{\delta_{F}}-\left(\frac{\varepsilon}{\varepsilon-1}\right) \tilde{e}_{t+s} P_{F, t+s}^{*}(j) \exp \left(\epsilon_{F, t+s}\right)\right]=0$,

and the aggregate price index for imports:

$$
P_{F, t}=\left[\left(1-\theta_{F}\right)\left(\tilde{P}_{F, t}\right)^{1-\varepsilon}+\theta_{F}\left(P_{F, t-1}\left(\frac{P_{F, t-1}}{P_{F, t-2}}\right)^{\delta_{F}}\right)^{1-\varepsilon}\right]^{\frac{1}{1-\varepsilon}}
$$

\subsection{Market Clearing}

Goods market clearing for domestic firms requires:

$$
\begin{aligned}
Y_{H, t}(i) & =C_{H, t}(i)+C_{H, t}^{*}(i)=\left(\frac{P_{H, t}(i)}{P_{H, t}}\right)^{-\varepsilon}\left[C_{H, t}+C_{H, t}^{*}\right], \\
& \Rightarrow Y_{t} \equiv \int_{0}^{1} Y_{H, t}(i) d i=C_{H, t}+C_{H, t}^{*},
\end{aligned}
$$

where

$$
C_{H, t}^{*}=\alpha\left(\frac{P_{H, t}^{*}}{P_{t}^{*}}\right)^{-\eta} C_{t}^{*} \quad \text { and } \quad Y_{t}^{*}=C_{t}^{*} .
$$

Market clearing for domestic bonds requires:

$$
B_{t}=0
$$

\footnotetext{
${ }^{10}$ The parameter $\theta_{F}$ governs the degree of ERPT.
} 


\subsection{The Log-Linearized Model}

The model is log-linearized around a deterministic zero-inflation steady state, where bond holdings are zero and the terms of trade are equal to $S_{s s}=1$. Let lowercase letters denote the log-deviations of the respective variables from their steady-state values: i.e., $x_{t}=\ln \left(X_{t} / X_{s s}\right)$. Loglinearizing the consumption Euler equation of the domestic household (10) yields:

$$
c_{t}-h c_{t-1}=\mathbb{E}_{t}\left(c_{t+1}-h c_{t}\right)-\frac{1-h}{\sigma}\left(r_{t}-\mathbb{E}_{t} \pi_{t+1}\right) .
$$

Log-linearizing (18) and (19) gives the aggregate supply condition for domesticproduced goods:

$$
\pi_{H, t}-\delta_{H} \pi_{H, t-1}=\beta \mathbb{E}_{t}\left(\pi_{H, t+1}-\delta_{H} \pi_{H, t}\right)+\frac{\left(1-\beta \theta_{H}\right)\left(1-\theta_{H}\right)}{\theta_{H}}\left(m c_{t}+\epsilon_{H, t}\right),
$$

where $\pi_{H, t}=p_{H, t}-p_{H, t-1}$ and

$$
m c_{t}=\varphi y_{t}-(1+\varphi) \epsilon_{a, t}+\alpha s_{t}+\frac{\sigma}{1-h}\left(c_{t}-h c_{t-1}\right)
$$

which is obtained after combining (9), (15), the aggregate version of (14), and noting that the log-linearized version of the CPI index (4) implies $p_{t}-p_{H, t}=\alpha s_{t}$ after using (6).

Log-linearizing (22) and (23) gives the aggregate supply condition for imported retail goods:

$$
\pi_{F, t}-\delta_{F} \pi_{F, t-1}=\beta \mathbb{E}_{t}\left(\pi_{F, t+1}-\delta_{F} \pi_{F, t}\right)+\frac{\left(1-\beta \theta_{F}\right)\left(1-\theta_{F}\right)}{\theta_{F}}\left(\psi_{F, t}+\epsilon_{F, t}\right),
$$

where $\pi_{F, t}=p_{F, t}-p_{F, t-1}$ and the law of one price gap $\psi_{F, t}$ is defined as:

$$
\psi_{F, t} \equiv e_{t}+p_{t}^{*}-p_{F, t}
$$

Log-linearizing equations (4)-(6) and using the above definition of $\psi_{F, t}$ yields the following relationship for the real exchange rate and the terms of trade:

$$
q_{t}=e_{t}+p_{t}^{*}-p_{t}=\psi_{F, t}+(1-\alpha) s_{t}
$$


First-differencing the log-linearized version of equation (6) yields:

$$
s_{t}-s_{t-1}=\pi_{F, t}-\pi_{H, t}+\epsilon_{s, t},
$$

where $\epsilon_{s, t}$ is an exogenous terms of trade shock, and first-differencing the log-linearized version of the CPI index (4) gives:

$$
\pi_{t}=(1-\alpha) \pi_{H, t}+\alpha \pi_{F, t},
$$

where $\pi_{t}=p_{t}-p_{t-1}$.

Under incomplete asset markets, the real interest rate parity condition is obtained by first-differencing (29) and combining with the log-linearized version of (11):

$$
\left(r_{t}-\mathbb{E}_{t} \pi_{t+1}\right)-\left(r_{t}^{*}-\mathbb{E}_{t} \pi_{t+1}^{*}\right)=\mathbb{E}_{t}\left(q_{t+1}-q_{t}\right)-\chi\left(d_{t}+\epsilon_{q, t}\right) .
$$

The disturbance term $\epsilon_{q, t}$ captures time-varying deviations from real interest rate parity. Log-linearizing the budget constraint (8) implies: ${ }^{11}$

$$
c_{t}+d_{t}=\frac{d_{t-1}}{\beta}-\alpha\left(s_{t}+\psi_{F, t}\right)+y_{t},
$$

where $d_{t}=\log \left(D_{t}\right) \equiv \log \left(\tilde{e}_{t} B_{t}^{*} / Y_{s s} P_{t}\right)$ is domestic-currency real foreign bond holdings (relative to steady-state output).

Under complete asset markets, equations (32) and (33) are replaced by the following log-linear real interest parity condition:

$$
\left(r_{t}-\mathbb{E}_{t} \pi_{t+1}\right)-\left(r_{t}^{*}-\mathbb{E}_{t} \pi_{t+1}^{*}\right)+\epsilon_{q, t}=\mathbb{E}_{t}\left(q_{t+1}-q_{t}\right) .
$$

Finally, the goods market clearing condition (24) implies:

$$
y_{t}=(1-\alpha) c_{t}+\alpha \eta q_{t}+\alpha \eta s_{t}+\alpha y_{t}^{*} \text {. }
$$

\footnotetext{
${ }^{11}$ Similar to Justiniano and Preston (2010), in equilibrium household nominal income $W_{t} N_{t}+\Pi_{t}=P_{H, t} Y_{t}+\left(P_{F, t}-\tilde{e}_{t} P_{t}^{*}\right) C_{F, t}$.
} 
We assume that the stochastic processes for technology, the terms of trade, and risk-premium shocks follow an independent $\mathrm{AR}(1)$ process:

$$
\epsilon_{x, t}=\rho_{x} \epsilon_{x, t-1}+v_{x, t}, \text { where } \rho_{x} \in(0,1), v_{x} \sim i i d\left(0, \sigma_{x}^{2}\right)
$$

for $x=a, s, q$, and the cost-push shocks in the domestic and retail sectors follow an i.i.d. process: $\epsilon_{H} \sim$ i.i.d. $\left(0, \sigma_{H}\right)$ and $\epsilon_{F} \sim$ i.i.d. $\left(0, \sigma_{F}\right)$. Following Kam et al. (2009), we further assume that the foreign country variables $\left\{\pi^{*}, y^{*}, r^{*}\right\}$ follow uncorrelated $\operatorname{AR}(1)$ processes:

$$
\left(\begin{array}{c}
\pi_{t}^{*} \\
y_{t}^{*} \\
r_{t}^{*}
\end{array}\right)=\left(\begin{array}{ccc}
a_{1} & 0 & 0 \\
0 & b_{2} & 0 \\
0 & 0 & c_{3}
\end{array}\right)\left(\begin{array}{c}
\pi_{t-1}^{*} \\
y_{t-1}^{*} \\
r_{t-1}^{*}
\end{array}\right)+\left(\begin{array}{ccc}
\sigma_{\pi^{*}} & 0 & 0 \\
0 & \sigma_{y^{*}} & 0 \\
0 & 0 & \sigma_{r^{*}}
\end{array}\right)\left(\begin{array}{l}
v_{\pi^{*}, t} \\
v_{y^{*}, t} \\
v_{r^{*}, t}
\end{array}\right)
$$

where $v_{\pi^{*}, t}, v_{y^{*}, t}, v_{r^{*}, t} \sim N\left(0, I_{3}\right)$.

Given the specification for monetary policy, the processes for $\left\{\epsilon_{a, t}, \epsilon_{q, t}\right.$, $\left.\epsilon_{s, t}\right\}$ and $\left\{\pi_{t}^{*}, y_{t}^{*}, r_{t}^{*}\right\}$ described by (36) and (37), and the cost-push shocks $\left\{\epsilon_{H, t}, \epsilon_{F, t}\right\}$, the respective system of equations (26)-(35) determines the following ten endogenous variables $\left\{c_{t}, y_{t}, d_{t}, q_{t}, s_{t}, \psi_{F, t}, r_{t}, \pi_{t}, \pi_{H, t}, \pi_{F, t}\right\}$ under IAM or nine endogenous variables under CAM, excluding $d_{t}$ from the vector.

\subsection{Central Bank Preferences}

As is standard in the literature, we assume that the central bank minimizes a one-period ad-hoc quadratic loss function where monetary policy targets inflation, the output gap, and interest rate smoothing. ${ }^{12}$ In addition, following Kam et al. (2009) the central bank can also target the real exchange rate. Consequently, the loss function is given by:

$$
L\left(\tilde{\pi}_{t}, y_{t}, q_{t}, r_{t}-r_{t-1}\right)=\frac{1}{2}\left[\tilde{\pi}_{t}^{2}+\mu_{y} y_{t}^{2}+\mu_{q} q_{t}^{2}+\mu_{r}\left(r_{t}-r_{t-1}\right)^{2}\right] .
$$

\footnotetext{
${ }^{12}$ An alternative approach would be to derive an approximate welfare-based loss function using the preferences of the household. While this approach is theoretically appealing (see, e.g., Woodford, 2003; Galí, 2015), it does not carry over easily to open economies (see, e.g., Benigno and Benigno, 2003; Monacelli, 2005). In particular, an accurate quadratic approximation of household welfare can be obtained in open economy models only under special assumptions on household preferences and on the value of the trade elasticity parameter $\eta$.
} 
The weight assigned to the annual inflation rate $\tilde{\pi}_{t} \equiv \sum_{i=0}^{3} \pi_{t-i} / 4$ is normalized to one and the weights $\mu_{y}, \mu_{q}, \mu_{r} \in[0,+\infty)$ represent the relative importance assigned to output gap stabilization, real exchange rate stabilization, and interest rate smoothing. The loss function specification given by (38) is consistent with flexible inflation targeting as described by Svensson (1999). Interest rate smoothing is included to capture monetary policy inertia. ${ }^{13}$ As discussed by Svensson (2000), the real exchange rate plays a prominent role in the monetary policy transmission mechanism in small open economies.

We further assume that the central bank minimizes (38) subject to the structural equations (26)-(35) under discretion. ${ }^{14}$ We employ the algorithm of Dennis (2007) to compute solutions to a linear-quadratic Markov perfect equilibrium (LQ-MPE) problem. ${ }^{15}$ Following Kam et al. (2009), we add a noise term $\epsilon_{r, t} \sim N\left(0, \sigma_{r}^{2}\right)$ to the resulting optimal interest rate rule $r_{t}\left(\epsilon_{t}, z_{t-1}\right)$ to capture imperfections in the setting of interest rates (i.e., an exogenous monetary policy shock).

\section{Estimation}

\subsection{Data}

To estimate the model we use quarterly data for each of the five LAIT countries. The Foreign economy is proxied by the United States (US). All data were downloaded from the IMF's International Financial Statistics, the OECD's National Accounts, and statistical tables published by the central bank of each country. Since the LAIT countries switched to IT at different periods during the late 1990s and early 2000s (see Table 1), the sample period differs for each country. To remove any country-specific noise in the data, the first few years of data after the adoption of IT are omitted from the sample. Specifically, the sample period for each country

\footnotetext{
${ }^{13}$ See Ilbas (2012) and McKnight and Mihailov (2015) for further discussion on the reasons behind its inclusion.

${ }^{14}$ When solving (38) under discretion, the central bank treats the problem as one of sequential optimization, whereas under commitment, the central bank credibly commits to a policy plan.

${ }^{15}$ For further details, see Dennis (2007) and Kam et al. (2009).
} 
used in the estimations is as follows: 2004:1 - 2014:4 for Brazil, 2002:1 2014:4 for Chile, 2003:1 - 2014:4 for Colombia, 2002:1 - 2014:4 for Mexico, and 2005:1 - 2014:4 for Peru.

For comparability with the closest literature, we estimate both asset market model versions, CAM and IAM, using the same 9 observables and the same 9 shocks as those in Kam et al. (2009). ${ }^{16}$ As the model features 9 exogenous shock processes $\left\{\epsilon_{a, t}, \epsilon_{q, t}, \epsilon_{r, t}, \epsilon_{s, t}, \epsilon_{H, t}, \epsilon_{F, t}, v_{\pi^{*}, t}, v_{r^{*}, t}, v_{y^{*}, t}\right\}$, 9 observable time series are needed to avoid stochastic singularity. For this reason, we treat $d_{t}$ in the IAM model version as a latent state variable and do not use it as a potential observable in the estimation. ${ }^{17}$ Thus, our data set contains the following 9 observable variables: imported goods inflation denominated in domestic currency $\left(\pi_{F, t}\right)$, the terms of trade (measured as the price of imports to exports) $\left(s_{t}\right)$, the real exchange rate (computed using the nominal exchange rate defined as national currency per 1 USD) $\left(q_{t}\right)$, domestic real GDP $\left(y_{t}\right)$, domestic CPI inflation $\left(\pi_{t}\right)$, the nominal interest rate $\left(r_{t}\right)$, US CPI inflation $\left(\pi_{t}^{*}\right)$, US real output $\left(y_{t}^{*}\right)$, and the US federal funds rate $\left(r_{t}^{*}\right)$. All variables are expressed in logs and detrended using the Hodrick-Prescott filter, except inflation rates and interest rates, which are expressed in quarterly percentage change. Since monetary policy in our framework is driven using an output gap methodology, for $y_{t}$ we use the Hodrick-Prescott filter to construct an output gap of deviations from the trend. As is customary in the estimation of DSGE models, all variables, including those in percentage terms, are demeaned to approximate theoretical deviations from the steady state.

In order to assess the role of the real exchange rate in the policy objective of each central bank, we follow Kam et al. (2009) in estimating two versions of the model, $\mu_{q}>0$ versus $\mu_{q}=0$ in (38), under both complete and incomplete asset markets to see which is more probable (given the same observables and shocks) via the comparison of Bayesian marginal likelihood (i.e., posterior odds, assuming equal prior model probabilities).

\footnotetext{
${ }^{16}$ In order to conduct a meaningful Bayesian model comparison pairwise, both asset markets structure versions need to be estimated using the same observable time series and the same number of shocks. For further discussion, see, e.g., Merola (2015).

${ }^{17}$ In the working paper version, McKnight et al. (2016), we also estimated the incomplete asset market model using 10 observables, by including a time-series for international currency reserves as a proxy for $d_{t}$ and adding a 10th shock process to preferences. Similar conclusions on central bank preference weights were obtained.
} 


\subsection{Methodology and Prior Selection}

The model $M$ is estimated using Bayesian methods. ${ }^{18}$ We update the $a$ priori beliefs about the parameter vector $\theta$, represented by the prior density $p(\theta \mid M)$ in view of the information contained in the observed sample $Y{ }^{19}$ According to Bayes Theorem (see, e.g., Herbst and Schorfheide, 2016),

$$
p(\theta \mid Y, M)=\frac{p(Y \mid \theta, M) p(\theta \mid M)}{\int p(Y \mid \theta, M) p(\theta \mid M) d \theta},
$$

this updating generates a posterior distribution $p(\theta \mid Y, M)$. The denominator in (39) is commonly known as the marginal likelihood of the data (or marginal data density) associated with $M$. As discussed by Herbst and Schorfheide (2016), among others, Bayesian inference amounts to characterizing the properties of the posterior distribution $p(\theta \mid Y, M)$. Usually, posterior samplers are employed that generate sequences of draws $\theta^{j}, j=1, \ldots, J$ from $p(\theta \mid Y, M)$. As is common in the literature, we apply the RandomWalk Metropolis-Hastings (RWMH) Markov Chain Monte Carlo (MCMC) algorithm to obtain draws from the posterior distribution. ${ }^{20}$ For each country, 2000000 RWMH-MCMC draws and 2500 Kalman filter iterations were obtained, where the first half of the draws was discarded (or burnt-in) in order to remove initial condition effects.

As the posterior density (39) is derived by combining the prior density $p(\theta \mid M)$ with the likelihood function $p(Y \mid \theta, M)$, the selection of priors for each parameter plays a fundamental role in Bayesian estimation. The priors used in our estimates are summarized in Table 2. As is customary, we conform to the established conventions in selecting the prior densities: we use the beta distribution for parameters in the interval $[0,1]$, the inverse

\footnotetext{
${ }^{18}$ Bayesian methods are described in detail in Gelman et al. (2004) and Koop (2006), among others. Their application to DSGE models has been expanding rapidly and includes key references such as Smets and Wouters (2003, 2007), An and Schorfheide (2007), Fernández-Villaverde et al. (2010), DeJong and Dave (2011), Del Negro and Schorfheide (2011), Miao (2014), Herbst and Schorfheide (2016), Fernández-Villaverde et al. (2016).

${ }^{19}$ The parameter vector $\theta$ describes the preferences, technology, central bank policy weights, and exogenous shock processes of the model $M$.

${ }^{20}$ The pseudo-code for this popular algorithm is detailed in Appendix B of Kam et al. (2009).
} 
gamma distribution for the standard deviations of the stochastic innovations $[0, \infty)$, and the gamma distribution for the rest.

Due to limited information in the data set, some structural parameters cannot be estimated with sufficient precision, and were therefore calibrated prior to estimation. For each country, we calibrate the import share in domestic consumption, $\alpha$, to values corresponding to the sample average share of imports of goods and services in consumption: we set $\alpha$ to 0.20 for Brazil; 0.51 for Chile; 0.29 for Colombia; 0.44 for Mexico; and 0.35 for Peru. ${ }^{21}$ As is common in the literature, for all countries the discount factor $(\beta)$ is fixed at 0.99 and the debt-elastic interest rate parameter $(\chi)$, appearing only in the IAM version, is fixed at 0.05 consistent with the estimates of Selaive and Tuesta $(2003 \mathrm{a}, \mathrm{b}) .^{22}$

We follow Kam et al. (2009) and assume that the prior distributions for the central bank preference parameters $\mu_{y}, \mu_{q}$, and $\mu_{r}$ are exactly the same. Consequently, any resulting differences in the posterior distributions of these (as well as the other) parameters will be due to the data itself.

\section{Results}

Table 3 summarizes the marginal likelihood across the four estimated model versions by country. For each of the five LAIT economies, tables 4 and 5 report the results of the Bayesian RWMH-MCMC estimation for the unrestricted $\left(\mu_{q}>0\right)$ and restricted $\left(\mu_{q}=0\right)$ model versions. Table 4 presents the results under the assumption of complete asset markets, whereas Table 5 summarizes the results under incomplete asset markets. Tables 4 and 5 also present a summary of the posterior mean and standard deviation estimates for the central bank preference weights obtained for each model version. Figures 1-5 depict, for the preferred model version by country, the estimated posterior distributions for the structural parameters. Tables

\footnotetext{
${ }^{21}$ These values correspond to the average quarterly share (in our whole sample, 1999:12014:4) of real imports of goods and services in real consumption by country. Since direct information for the latter ratio is usually not released in statistical publications, we obtained it indirectly, by the ratio of the average quarterly share of real imports of goods and services in GDP to the average quarterly share of real consumption in real GDP.

${ }^{22}$ Using GMM, Selaive and Tuesta $(2003 \mathrm{a}, \mathrm{b})$ estimate $\chi$ to be in the range of 0.004 and 0.071 for a sample of OECD countries.
} 
6-10 report the corresponding posterior estimates and convergence diagnostics for both the structural parameters and the persistence and standard deviations of the shocks, again, for the preferred model version. ${ }^{23}$

\subsection{Complete versus Incomplete Asset Markets: Bayesian Model Comparison}

We begin the discussion of our estimation results by first performing a Bayesian comparison between the model versions under complete and incomplete asset markets. Table 3 summarizes the marginal likelihoods for the $\mu_{q}>0$ (unrestricted) and $\mu_{q}=0$ (restricted) cases under both the CAM and IAM model versions. More precisely, the (log-) marginal likelihood, $\ln p\left(Y \mid M_{i}\right)$ or $\ln p\left(Y \mid M_{j}\right)$, for each of these pairs of models by country, $M_{i}$ or $M_{j}$, is compared, based on using the common data set, $Y$. The highest marginal likelihood per country is typed in bold fonts. By inspection of Table 3, it is clear that for all LAIT countries and the two model specifications considered, $\mu_{q}>0$ (unrestricted) and $\mu_{q}=0$ (restricted), the complete asset markets version is unanimously preferred by the data.

We also note that, according to the typical Bayesian model comparison criteria (e.g., Kass and Raftery, 1995), the superiority of the highest marginal likelihood over the second largest marginal likelihood for each country is always sufficiently large to ensure very strong statistical evidence in favor of the complete asset markets version. Using the value of the Kass-Raftery (1995, p. 777) criterion of the Bayes factor $\left(B F_{i j}\right)$ for two estimated and compared models $i$ and $j, 2 \ln B F_{i j} \equiv 2 \ln \frac{p\left(y \mid M_{i}\right)}{p\left(y \mid M_{j}\right)}>|10|$, it can be verified in Table 3 that this criterion is satisfied marginally even in the "tightest" case, Colombia, and much more convincingly in all the remaining four LAIT countries.

It is important to note that the summary statistics for the Bayesian estimation reported in tables 4 (CAM) and 5 (IAM) (involving 20 sets of estimated results) are overall of a good quality. ${ }^{24}$

\footnotetext{
${ }^{23}$ All figures and tables for the other model versions are available online in the zip replication archive provided as supplementary material.

${ }^{24}$ For three cases of the IAM model version, the acceptance rate is too low (below $5 \%$ ) and the indeterminacy rate is too high (above 40\%).
} 
Focusing on the results reported in the columns of Table 4 under the preferred CAM model reveals that the model specification with explicit concern for real exchange rate stabilization is favored for nearly all LAIT central banks. With the exception of Peru, the results suggest that the model $\mu_{q}>0$ is a better fit of the data in terms of having a statistically meaningful higher marginal likelihood.

For each model specification, Table 4 also summarizes the parameter estimates associated with the loss function of each central bank. By inspection, while there is significant heterogeneity in terms of the specific parameter weights estimated for each country, three main conclusions arise. First, there is significant evidence that all five central banks are concerned about smoothing the nominal interest rate. In particular, relative to the weight of inflation stabilization (normalized at 1), we find that Chile (1.14) and Peru (1.78) place very high weights on interest rate smoothing. Although Colombia is found to have the lowest weight, this is still sizable (0.35). For the four countries concerned about real exchange rate volatility (i.e., where the $\mu_{q}>0$ model version is preferable in terms of marginal likelihoods), the estimates for Colombia (0.10) and Mexico (0.06) yield low weights, suggesting the low importance of real exchange rate stabilization in these countries. In stark contrast, both Brazil and Chile assign significant identical weights to real exchange rate stabilization (0.31). In the case of Chile, this is nearly double the weight assigned to output gap stabilization (0.17). Third, while Mexico and Peru show little concern for output gap stabilization, Brazil (0.73), Colombia (0.44), and Chile (0.17) place a sizeable weight on it. Overall, Peru, and less so, Mexico are found to be strict inflation targeters, whereas Brazil, Colombia, and Chile are flexible inflation targeters that include other macroeconomic policy objectives other than inflation.

It is important to stress the role of the asset market structure in generating these findings. By inspection of Table 5, while all five LAITs now support the unrestricted model $\left(\mu_{q}>0\right)$ under IAM, only Mexico assigns a sizeable weight $(0.37)$ to real exchange rate stabilization. Now all five LAITs come out as flexible inflation targeters, with the estimated weight of output stabilization varying from 0.17 in Brazil to 0.83 in Chile. What is less controversial is that all five LAITs assign usually the strongest weight 
(after that of inflation) to interest rate smoothing, no matter the asset market structure. The above exercise highlights the sensitivity of the Bayesian estimates for the central bank policy weights to the assumption of international asset markets (in)completeness. Our analysis thus emphasizes the importance of performing a model comparison of alternative asset markets assumptions in Bayesian estimation, in order to distinguish which asset market structure is a better fit of the data, such that the central bank preferences uncovered are not misspecified. ${ }^{25}$

\subsection{Posterior Shapes and Convergence Diagnostics}

Figures 1-5 show both the assumed prior (dashed curve) and the estimated posterior (solid curve) distributions (also indicating the posterior mean by the vertical line) for each structural parameter for the five LAIT economies. To save space, we only include in these figures and the subsequent tables the model version that was preferred (across the four models studied) by the Bayesian comparison exercise discussed above. ${ }^{26}$ By inspection, the posterior distributions are generally unimodal and nicely shaped in most cases. However, there are a few exceptions. For, instance, the coefficient of relative risk aversion, $\sigma$, is not estimated with a good degree of precision for all our five countries except Chile, and this can be seen in the respective figures as well as by checking the convergence diagnostics in the respective subsequent tables 6-10. Estimation is sometimes not satisfactory for the standard deviations of the shock process innovations either, as can be seen in these tables. While these two issues are common problems, e.g., also reflected in the estimation results reported by Kam et al. (2009), there are some further problems here in the LAIT context, e.g., affecting the convergence diagnostics of some structural parameters, and in particular some of the policy weights. We mention this as a note of caution, as those remaining issues could not be removed after many attempts of re-estimation and fine-tuning.

\footnotetext{
${ }^{25}$ Rabanal and Tuesta (2010) find that the asset markets structure affects the degree of model misspecification and changes significantly the Bayesian estimates, including the reported policy parameters.

${ }^{26}$ Analogous figures for the remaining model versions for each country are available online in the zip replication archive provided as supplementary material.
} 
Tables 6-10 report the posterior mean and standard deviation estimates, the $95 \%$ confidence sets for the posterior estimates, and selected diagnostic tests for MCMC convergence. In these tables, NSE stands for the numerical standard error, which approximates the true posterior moment as proposed by Geweke (1992). The NSE reported for each country uses an $8 \%$ autocovariance tapered estimate. The $\mathrm{G}$ p-values report the p-value associated with Geweke's (1992) chi-squared convergence test. ${ }^{27}$ The last column of tables 6-10 reports the Brooks-Gelman (B-G) univariate shrink factor proposed by Gelman and Rubin (1992) and extended by Brooks and Gelman (1998). ${ }^{28}$ By inspection of tables 6-10, we can conclude that our estimation results are overall satisfactory. The reported convergence test statistics for the estimated parameters indicate that in general the latter converge to an invariant distribution. ${ }^{29}$ There are few exceptions, however, where the Geweke chi-squared convergence test and the univariate shrink B-G factor both agree on problems with convergence: $\sigma, \rho_{q}, \mu_{r}$, and $\sigma_{s}$ for Chile; $\rho_{q}$ for Colombia; $\sigma, \rho_{q}$, and $\mu_{r}$ for Mexico; $\theta_{F}$ and $\sigma_{a}$ for Peru. ${ }^{30}$

\subsection{Estimated Structural Parameters Influencing the Endogenous Propagation}

We now check if the estimated key structural parameters that drive the endogenous propagation mechanism are economically plausible, and how they compare to analogous earlier estimates.

We obtain estimates for habit persistence that, except for Chile, are lower than those for advanced economies in the related literature: posterior mean of 0.91 for Chile, 0.40 for Colombia, 0.38 for Peru, 0.37 for Mexico, and 0.30 for Brazil. Our estimates of the coefficient of relative risk aversion

\footnotetext{
${ }^{27}$ If the Markov chain of draws has converged to a stable distribution, one would expect the means from the two halves of the generated sample to be statistically indistinguishable. The null hypothesis of the test is that the means are equal. Thus, a low p-value may indicate some evidence of problems in convergence.

${ }^{28}$ This test runs the chain two or more times from a widely-dispersed starting point to see if the Markov chain always converges to the same value. Commonly, a B-G factor below 1.1 is considered as little evidence of dispersion (see, e.g., Gelman et al., 2004).

${ }^{29}$ The MCMC diagnostics figures illustrating the convergence results discussed here are available online in the zip replication archive provided as supplementary material.

${ }^{30}$ Note that Kam et al. (2009) report similar problems for some of the parameters we enumerated for Australia, Canada, and New Zealand.
} 
vary considerably across the five LAIT countries, but also bear in mind that the convergence diagnostics were not reliable for this parameter estimate: Brazil (1.82), Colombia (1.77), and Mexico (1.15) are found to have relatively higher CRRA estimates, while Chile (0.20) and, notably, Peru (0.01) are found to have a low degree of estimated relative risk aversion. The inverse of the Frisch elasticity of labor supply is estimated within the usual range, 1.51 in Brazil, 1.87 in Chile, 1.49 in Colombia, 1.47 in Mexico, and 1.58 in Peru. The estimated elasticity of substitution between home and foreign goods stays always within the typical range of estimates found in the empirical literature of 0.1-2.0 (see, e.g., Corsetti et al., 2008): 1.18 for Brazil, 0.11 for Chile, 0.79 for Colombia, 0.67 for Mexico, and 1.22 for Peru.

The degree of domestic-output versus import price stickiness is consistently estimated across all five LAIT countries to be, roughly, one-and-ahalf to twice higher in favor of the domestic sector: 0.85 versus 0.80 for Brazil; 0.39 versus 0.27 for Chile; 0.77 versus 0.14 for Colombia; 0.87 versus 0.63 for Mexico; and 0.75 versus 0.38 for Peru. The backward-lookingness of the NKPC for home prices versus that for import prices is estimated at 0.93 versus 0.07 in Brazil, 0.60 versus 0.61 in Chile, 0.95 versus 0.31 in Colombia, 0.98 versus 0.92 in Mexico, and 0.18 versus 0.52 in Peru.

\subsection{Estimated Persistence and Volatility of the La- tent Exogenous Shock Processes}

We now turn to the sources of exogenous fluctuations in the LAIT economies, presenting our set of estimates for persistence and volatility of the structural shock processes we included in our model. ${ }^{31}$

As it was thus far, the estimated persistence of the domestic exogenous shock processes across our five LAIT economies reveals some common features as well as some country-specific differences. The most persistent domestic shock for Brazil (0.90), Chile (0.88), Colombia (0.86), and Mexico (0.66) is the risk-premium shock, whereas for Peru (0.86) the technology

\footnotetext{
${ }^{31}$ The prior and posterior figures per country, illustrating the results discussed in the present subsection, are available online in the zip replication archive provided as supplementary material.
} 
shock dominates in terms of persistence. Overall, the least persistent domestic shock in four of our five LAIT economies is the terms-of-trade shock (ranging from 0.21 in Colombia to 0.33 in Mexico), but in Chile the technology shock is the least persistent (0.27).

Looking at the estimated volatility (measured by the posterior mean of the standard deviation) of the exogenous shock processes, our main findings can be summarized as follows. The foreign interest rate shock has the lowest standard deviation in Chile (0.20), Mexico (0.21), and Peru (0.25), whereas in Brazil and Colombia the domestic interest rate shock has a lower estimated standard deviation than the foreign one ( 0.40 vs. 0.54 and 0.34 vs. 0.53, respectively). In Brazil (23.96) and Colombia (24.22), the costpush shock in the imported goods sector dominates, together with that in the domestic economy and the terms-of-trade shock. In Chile, the terms-oftrade shock (12.80) displays the highest volatility, followed by the cost-push shock in the imported goods sector (9.27), and the technology shock (8.53). In Peru, the risk-premium shock (18.96) is the most volatile, followed by the technology shock (13.10) and the cost-push shock in the imported goods sector (11.03). Overall, the terms of trade shock is of a significant and comparable magnitude in all five LAIT economies, except Mexico (0.39), with an estimated standard deviation ranging from 8.37 in Peru to 15.33 in Brazil. In Chile (8.53), Mexico (14.28), and Peru (13.10), the technology shock plays an important role in driving volatility, whereas in Brazil (1.89) and Colombia (2.01) it is of a modest, if not non-negligible magnitude. Our estimates, therefore, show the dominance in generating volatility of the terms-of-trade, cost-push, and technology shocks for most if not all five LAIT economies. Only in Peru is the risk-premium shock an important source of exogenous disturbances, indeed of the highest magnitude (18.96) compared to the other shocks in this country.

\subsection{Comparing Central Bank Mandates with Esti- mated Policy Preference Weights}

In this subsection, we briefly compare the estimated target weights in the central bank loss functions reported in Table 4 against their actual mandates. Dincer and Eichengreen (2014) argue that Latin America and the 
Caribbean is a region with low central bank transparency. In this sense, our results help to shed some light on the decision-making behavior of central banks. Our loss function estimates are derived from observed outcomes, and thus allow us to assess whether the actions of central banks are broadly consistent with their legal mandates.

Among the central banks analyzed in this paper, the Central Bank of Brazil (BCB) is a special case. While the $\mathrm{BCB}$ enjoys administrative autonomy, it is not fully independent, as the Executive Branch may remove the members of the bank's board of directors at any time. Additionally, the law establishes that BCB's goals are fully subordinated to the National Monetary Council (CMN), presently composed by the Minister of Finance, the Minister of Planning, Development and Management, and the Governor of the BCB. ${ }^{32}$ As a result, price stability is not the explicit primary mandate (Carrière-Swallow et al., 2016), even after adopting an IT regime in 1999. Given these antecedents, it can be expected that monetary policy in Brazil would place a non-negligible weight to output gap and real exchange rate stabilization. Indeed, our results uncovered that BCB assigns the highest value among all five LAIT central banks to both output gap (0.73) and real exchange rate (0.31) stabilization.

For the four remaining LAIT countries, the legal framework is very similar: price stability is the main policy objective for the central banks in Chile, Colombia, Mexico, and Peru. In the cases of Colombia, Mexico, and Peru, this goal was elevated to the constitutional level. ${ }^{33}$ The stronger legal foundation might explain why Mexico and Peru come closer to implementing a strict IT regime in our results.

\section{Conclusions}

The objective of this paper was to uncover and compare the central bank preferences of the five LAIT countries operating under a floating exchange-

\footnotetext{
${ }^{32}$ Law 4595 , enacted in 1964, establishes that "It is the responsibility of the BCB to comply with and ensure compliance with the provisions attributed to it by current legislation and norms issued by the National Monetary Council".

${ }^{33}$ Article 373 of the Constitution of Colombia, Article 28 of the Constitution of Mexico, and Article 84 of the Constitution of Peru clearly mention price stability to be the main goal of the Central Bank.
} 
rate regime using Bayesian estimation. We employed a medium-scale New Keynesian small open economy model that assumed imperfect ERPT and either complete or incomplete international asset markets. Optimal monetary policy was modeled under discretion, where the central bank minimized a quadratic loss function with four policy objectives: inflation control, output gap stabilization, real exchange rate volatility reduction, and nominal interest rate smoothing. The weight attributed to each policy objective, which depends on the country-specific institutional preferences of each central bank, was represented in terms of Bayesian posterior distributions and convergence diagnostics.

The key insights of our analysis can be summarized as follows. In terms of the typical Bayesian model comparison criteria, we found very strong statistical evidence in favor of the complete asset markets model over the incomplete asset markets version. The five LAIT economies we considered seem to fall broadly into two groups. The first group consists of Mexico and Peru whose priority targets are to stabilize inflation with a significant degree of nominal interest rate smoothing, consistent with the adoption of a strict IT regime. The second group, Brazil, Chile, and Colombia, have broader policy objectives where each central bank additionally cares about output gap stabilization consistent with flexible IT. No evidence of stabilizing the real exchange rate is found for Peru. While we, further, find evidence that the central banks of Brazil, Chile, Colombia, and Mexico are concerned about real exchange rate volatility, only Brazil and Chile are found to assign sizeable weight to reducing its fluctuations. Finally, we verified that the estimated preference weights of the five LAIT central banks credibly reflect their legal mandates.

This work can be improved along various dimensions. It could be possible that preferences were not constant over this period. Personalities of governors, in addition to the legal mandate of the institution itself, could also shape the preferences of the central bank. For future research, it would therefore be interesting to study separate subperiods in the institutional history or in governor terms of office within a central bank, and compare across such subperiods the estimated policy preference parameters. 
Acknowledgement: We are grateful to an anonymous referee and the Co-Editor David VanHoose, as well as to Arnab Bhattacharjee, Julio Carrillo, Atanas Christev, Alex Cukierman, Jesús Fernández-Villaverde, Kólver Hernández, Timothy Kam, Alberto Ortiz, Giovanni Pellegrino, Jessica Roldán, George Tauchen, and Konstantinos Theodoridis for helpful comments and suggestions. Feedback from the audiences at seminars at Banco de México, El Colegio de México, University of Reading, HeriotWatt University, at the workshops on "How Should DSGE Models Be Estimated?" (2015) and on "Bayesian Computation" (2016) both held at the University of Reading, at the 2016 LACEA-LAMES meetings, the 2017 ICMAIF/Rethymno conference, the 2018 RES conference, the 2018 GdRE in Money, Banking in Finance symposium, the 2018 European Workshop on Political Macroeconomics, and the 2018 SCE/CEF meeting is also acknowledged. We are indebted to Timothy Kam and Alejandro Justiniano for kindly providing their Matlab codes. The usual disclaimer applies. The views expressed herein are those of the authors and do not necessarily reflect those of Banco de México. 


\section{References}

[1] Adolfson, M., Laseen, S., Lindé, J., Villani, M., 2007. Bayesian estimation of an open economy DSGE model with incomplete pass-through. Journal of International Economics 72, 481-511.

[2] Alonso-Carrera, J., Kam, T., 2016. Anatomizing incomplete-markets small open economies: policy trade-offs and equilibrium determinacy. Macroeconomic Dynamics 20, 1022-1050.

[3] An, S., Schorfheide, F., 2007. Bayesian analysis of DSGE models. Econometric Reviews 26, 211-219.

[4] Batini, N., Laxton, D., 2007. Under what conditions can inflation targeting be adopted? The experience of emerging markets, in Mishkin, F., Schmidt-Hebbel, K. (Eds.), Monetary Policy under Inflation Targeting. Central Bank of Chile, Santiago, 1-38.

[5] Benigno, G., Benigno, P., 2003. Price stability in open economies. Review of Economic Studies 70, 743-764.

[6] Benigno P., 2009. Price stability with imperfect financial integration. Journal of Money, Credit and Banking 41(s1), 121-149.

[7] Bernanke, B., Mishkin, F., 1997. Inflation targeting: A new framework for monetary policy. Journal of Economic Perspectives 11, 97-116.

[8] Brooks, S. P., Gelman, A., 1998. General methods for monitoring convergence of iterative simulations. Journal of Computational and Graphical Statistics 7, 434-455.

[9] Brito, R., Bystedt, B., 2010. Inflation targeting in emerging economies: Panel evidence. Journal of Development Economics 91, 198-210.

[10] Calvo, G., 1983. Staggered prices in a utility maximizing framework. Journal of Monetary Economics 12, 383-398.

[11] Capistrán, C., Ramos-Francia, M., 2010. Does inflation targeting affect the dispersion of inflation expectations? Journal of Money, Credit and Banking 42, 113-134. 
[12] Carare, A., Stone, M., 2006. Inflation targeting regimes. European Economic Review 50, 1297-1315.

[13] Carrière-Swallow, Y., Jácome L. I., Magud, N. E., Werner, A. M., 2016. Central banking in Latin America: The way forward, IMF Working Paper 16/197, International Monetary Fund.

[14] Castelnuovo, E., Surico., P., 2004. Model uncertainty, optimal monetary policy and the preferences of the Fed. Scottish Journal of Political Economy 51, 105-126.

[15] Chari, V. V., Kehoe, P. J., McGrattan, E. R., 2002. Can sticky price models generate volatile and persistent real exchange rates? Review of Economic Studies 69, 533-563.

[16] Corsetti, G., Dedola, L., Leduc, S., 2008. International risk sharing and the transmission of productivity shocks. Review of Economic Studies $75,443-473$.

[17] Del Negro, M., Schorfheide, F., 2011. Bayesian macroeconometrics, in Geweke, J., Koop, G., van Dijk, H. (Eds.), The Oxford Handbook of Bayesian Econometrics, Oxford: Oxford University Press (Ch. 7).

[18] DeJong, D., Dave, C., 2011 (2nd ed.). Structural Macroeconometrics, Princeton, NJ, and Oxford, England: Princeton University Press.

[19] Dennis, R., 2007. Optimal policy in rational expectations models: New solution algorithms. Macroeconomic Dynamics 11, 31-55.

[20] Dincer, N. N., Eichengreen, B., 2014. Central bank transparency and independence: Updates and new measures, International Journal of Central Banking 10, 189-259.

[21] Fernández-Villaverde, J., Guerron-Quintana, P., Rubio-Ramírez, J. F., 2010. The new macroeconometrics: A Bayesian approach, in O'Hagan, A., West, M. (Eds.), Handbook of Applied Bayesian Analysis. Oxford: Oxford University Press.

[22] Fernández-Villaverde, J., Rubio-Ramírez, J. F., Schorfheide, F., 2016. Solution and estimation methods for DSGE models, in Taylor, J. and 
Uhlig, H. (Eds.), Handbook of Macroeconomics, Vol. 2, 527-724, Elsevier.

[23] Galí, J., 2015 (2nd ed.). Monetary Policy, Inflation and the Business Cycle: An Introduction to the New Keynesian Framework and Its Applications, Princeton, NJ, and Oxford, England: Princeton University Press.

[24] Galí, J., Monacelli, T., 2005. Monetary policy and exchange rate volatility in a small open economy. Review of Economic Studies 72, $707-734$.

[25] Gelman, A., Carlin, J. B., Stern, H. S., Rubin, D. B., 2004 (2nd ed.), Bayesian Data Analysis, Chapman \& Hall/CRC.

[26] Gelman, A., Rubin, D. B., 1992. Inference from iterative simulation using multiple sequences. Statistical Science 7, 457-511.

[27] Geweke, J., 1992. Evaluating the accuracy of sampling-based approaches to calculating posterior moments, in Bernardo, J. M., Berger, J. O., Dawid, A. P., Smith, A. F. M. (Eds.), Bayesian Statistics 4, Oxford, UK: Clarendon Press.

[28] Goncalves, C., Salles, J., 2008. Inflation targeting in emerging economies: What do the data say? Journal of Development Economics $85,312-318$.

[29] Hammond, G., 2011. State of the Art of Inflation Targeting, Centre for Central Banking Studies Handbook No. 29, London: Bank of England.

[30] Herbst, E., Schorfheide, F., 2016. Bayesian Estimation of DSGE Models, Princeton, NJ, and Oxford, England: Princeton University Press.

[31] Ilbas, P., 2010. Estimation of monetary policy preferences in a forwardlooking model: A Bayesian approach. International Journal of Central Banking 6, 169-209.

[32] Ilbas, P., 2012. Revealing the preferences of the US Federal Reserve. Journal of Applied Econometrics 27, 440-473. 
[33] International Monetary Fund, 2012. Annual Report on Exchange Arrangements and Exchange Restrictions, IMF: Washington, DC.

[34] Jahan, S., 2012. Inflation targeting: Holding the line. Finance \& Development (online: updated on March 28, 2012).

[35] Justiniano, A., Preston, B., 2010. Monetary policy and uncertainty in an empirical small open-economy model. Journal of Applied Econometrics 25, 93-128.

[36] Kam, T., Lees, K., Liu, P., 2009. Uncovering the hit list for small inflation targeters: A Bayesian structural analysis. Journal of Money, Credit and Banking 41, 583-618.

[37] Kass, R. E., Raftery, A. E., 1995. Bayes factos. Journal of the American Statistical Association 90(430), 773-795.

[38] Kollmann R., 2002. Monetary policy rules in the open economy: effects on welfare and business cycles. Journal of Monetary Economics 49, 989-1015.

[39] Koop, G., 2006 (reprinted with corrections / 2003, 1st ed.). Bayesian Econometrics. Chichester, England: John Wiley and Sons.

[40] Lee, W., 2011. Comparative case studies of the effects of inflation targeting in emerging economies. Oxford Economic Papers 63, 375397.

[41] Lin, S., Ye, H., 2009. Does inflation targeting make a difference in developing countries? Journal of Development Economics 89, 118-123.

[42] Lubik, T. A., Schorfheide, F., 2007. Do central banks respond to exchange rate movements? A structural investigation. Journal of Monetary Economics 54, 1069-1087.

[43] McKnight, S., Mihailov, A., 2015. Do real balance effects invalidate the Taylor principle in closed and open economies? Economica 82 (328), 938-975. 
[44] McKnight, S., Mihailov, A., Pompa Rangel, A. 2016. What do Latin American inflation targeters care about? A comparative Bayesian estimation of central bank preferences. Economics \& Management Discussion Paper 129, Department of Economics, University of Reading.

[45] Merola, R., 2015. The role of financial frictions during the crisis: An estimated DSGE model. Economic Modelling 48, 70-82.

[46] Miao, J., 2014. Economic Dynamics in Discrete Time, Cambridge, MA, and London, England: MIT Press.

[47] Mishkin, F. S., Schmidt-Hebbel, K., 2001. One decade of inflation targeting in the world: What do we know and what do we need to know? NBER Working Paper 8397.

[48] Monacelli, T., 2005. Monetary policy in a low pass-through environment. Journal of Money, Credit and Banking 37, 1047-1066.

[49] Palma, A. A., Portugal, M. S., 2014. Preferences of the Central Bank of Brazil under the inflation targeting regime: Estimation using a DSGE model for a small open economy. Journal of Policy Modeling $36,824-839$.

[50] Rabanal, P., Tuesta, V., 2010. Euro-Dollar real exchange rate dynamics in an estimated two-country model: An assessment. Journal of Economic Dynamics \& Control 34, 780-797.

[51] Roger, S., 2010. Inflation targeting turns 20. Finance \& Development 47, No. 1, 46-49.

[52] Schmitt-Grohé, S., Uribe, M., 2003. Closing small open economy models. Journal of International Economics 61, 163-185.

[53] Selaive, J., Tuesta, V., 2003a. Net foreign assets and imperfect passthrough: The consumption-real exchange rate anomaly. Board of Governors of the Federal Reserve System, International Finance Discussion Paper 764 . 
[54] Selaive, J., Tuesta, V., 2003b. Net foreign assets and imperfect financial integration: An empirical approach. Central Bank of Chile Working Paper 252.

[55] Smets, F., Wouters, R., 2003. An estimated dynamic stochastic general equilibrium model of the Euro area. Journal of the European Economic Association 1, 1123-1175.

[56] Smets F., Wouters, R., 2007. Shocks and frictions in US business cycles: A Bayesian DSGE approach. American Economic Review 97, 586-606.

[57] Svensson, L. E. O., 1999. Inflation targeting as a monetary policy rule. Journal of Monetary Economics 43, 607-654.

[58] Svensson, L. E. O., 2000. Open-economy inflation targeting. Journal of International Economics 50, 155-183.

[59] Taylor, J. B., 1993. Discretion versus policy rules in practice. CarnegieRochester Conference Series on Public Policy 39, 195-214.

[60] Uribe, M., Yue, V. Z., 2006. Country spreads and emerging countries: Who drives whom? Journal of International Economics 69, 6-36.

[61] Woodford, M., 2003. Interest Rates and Prices: Foundations of a Theory of Monetary Policy, Princeton, NJ: Princeton University Press. 


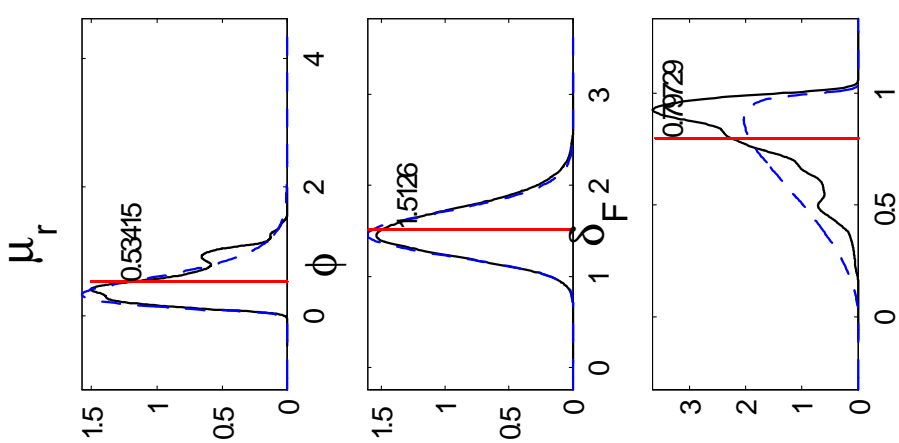

0
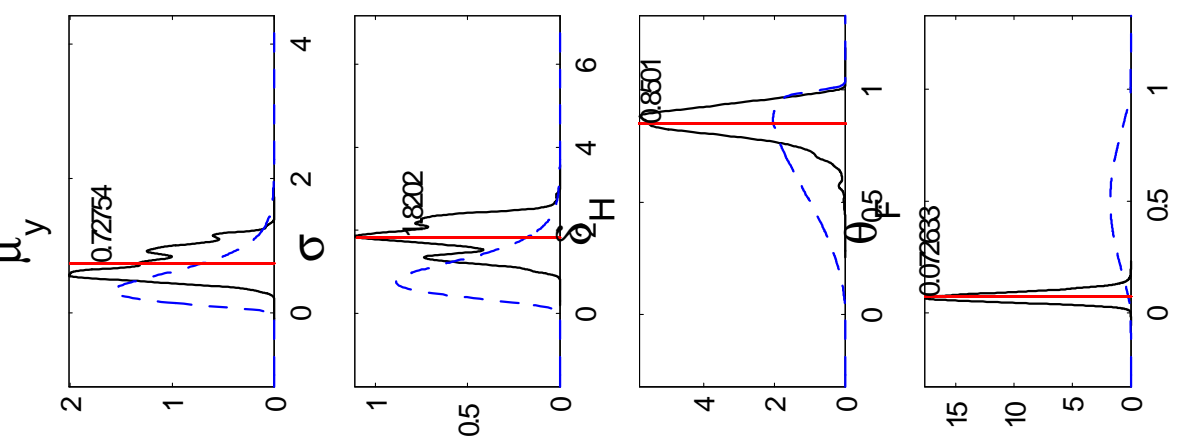

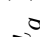

$\sum_{0}^{2}$

वृ.
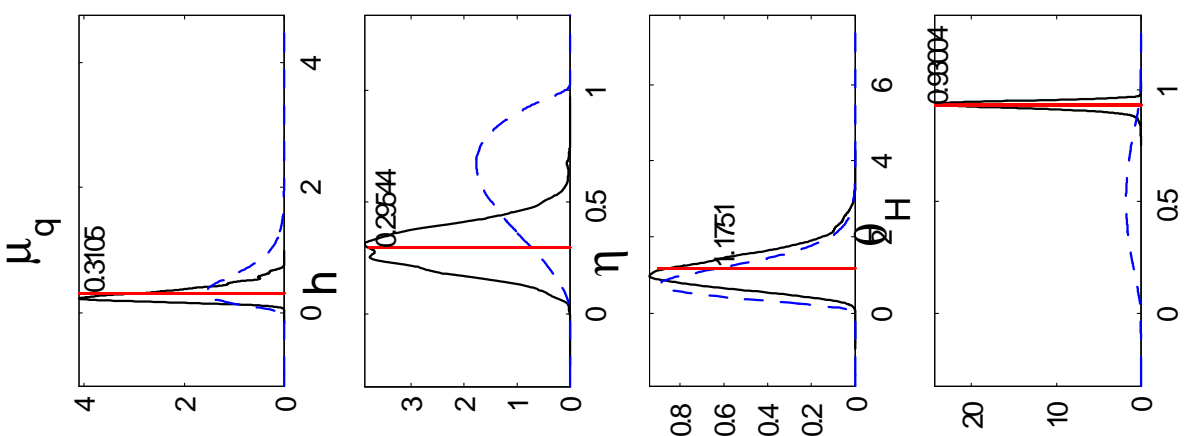

苛 


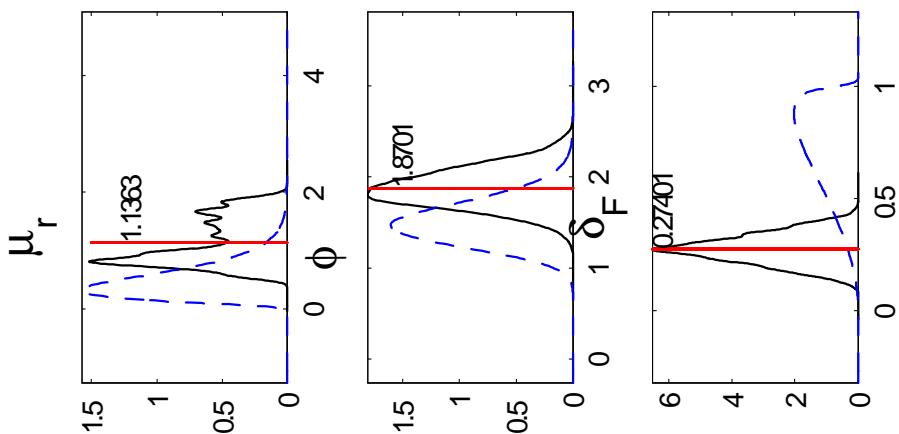

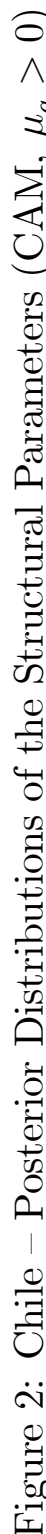

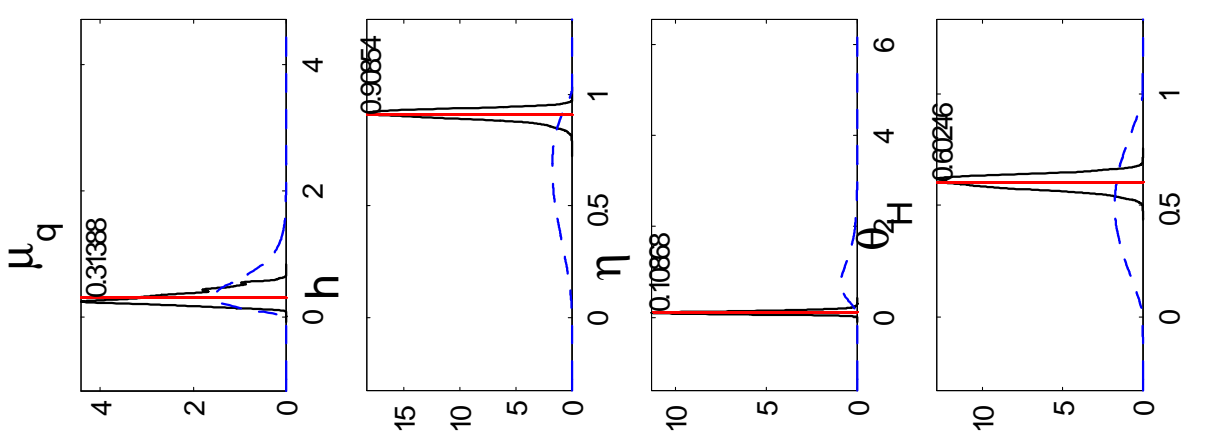



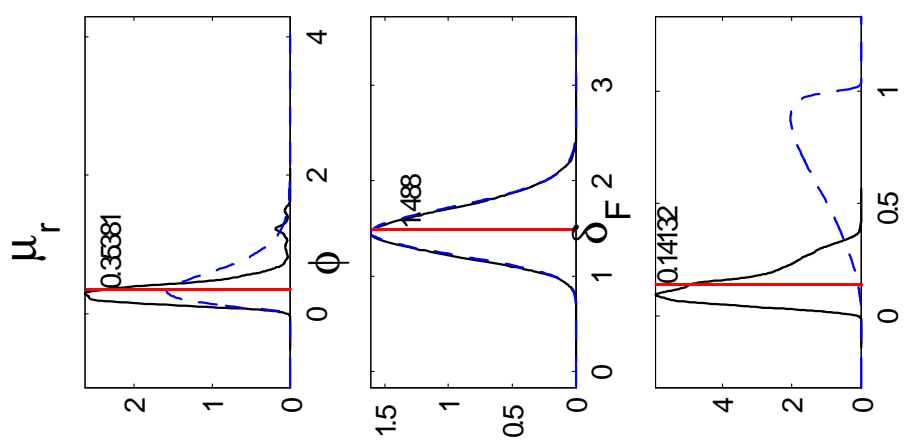

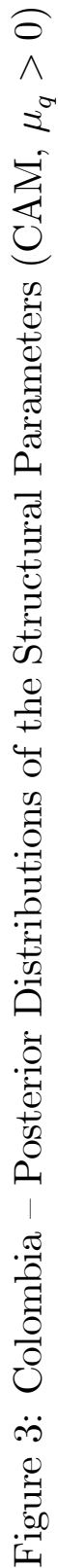
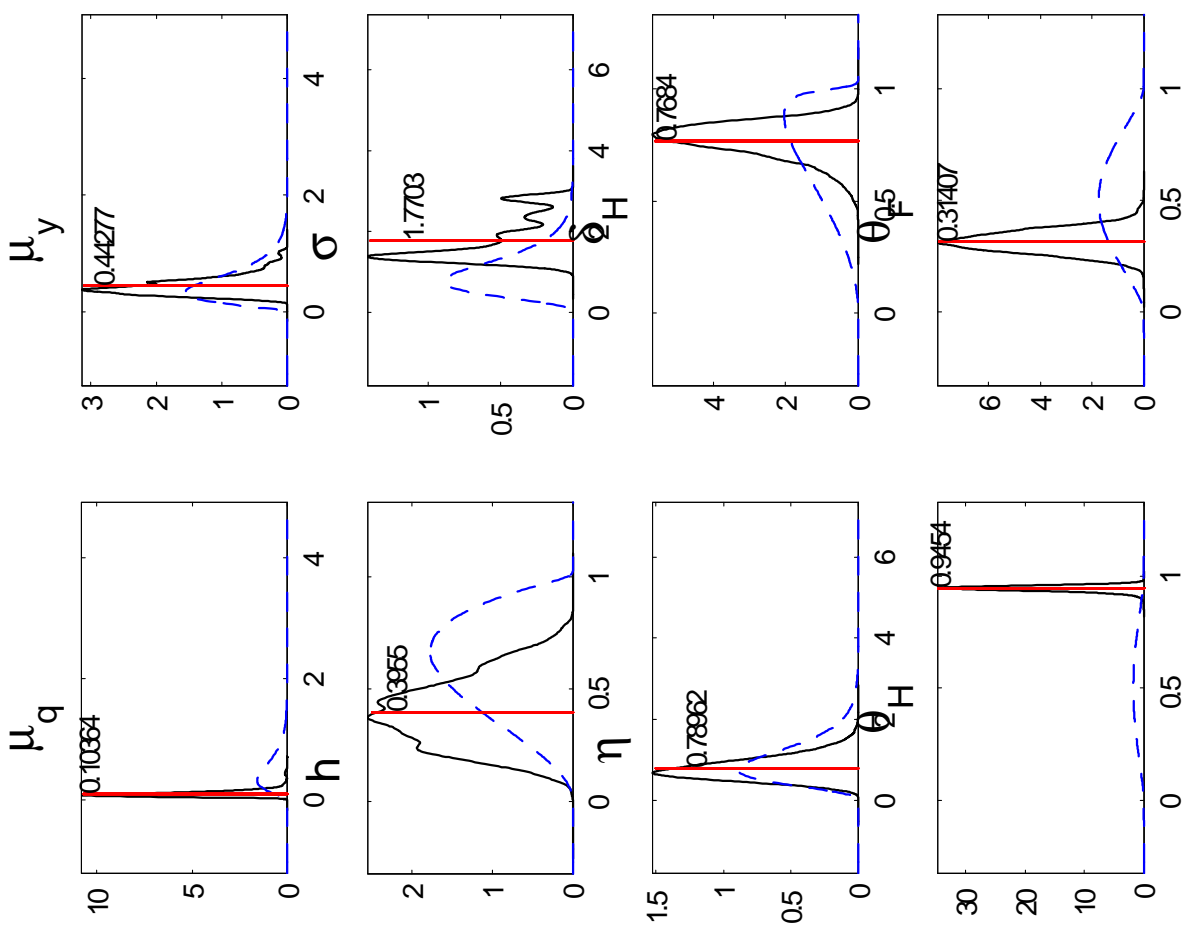

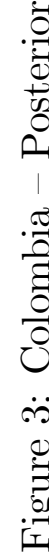




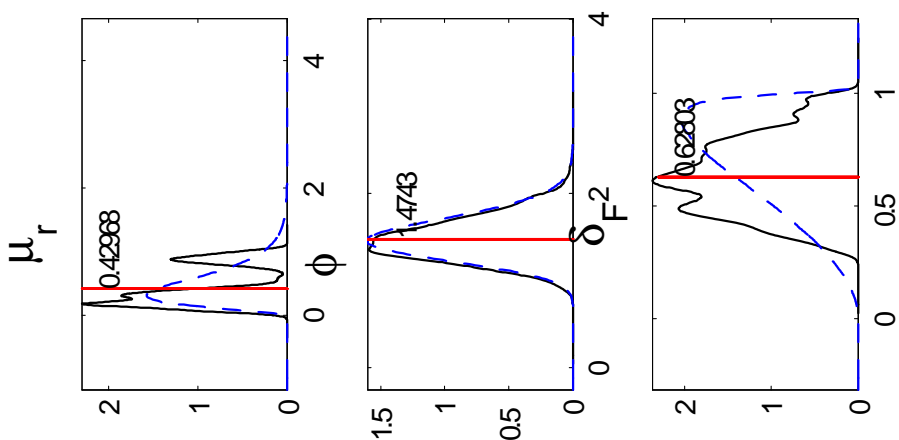

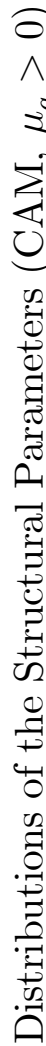
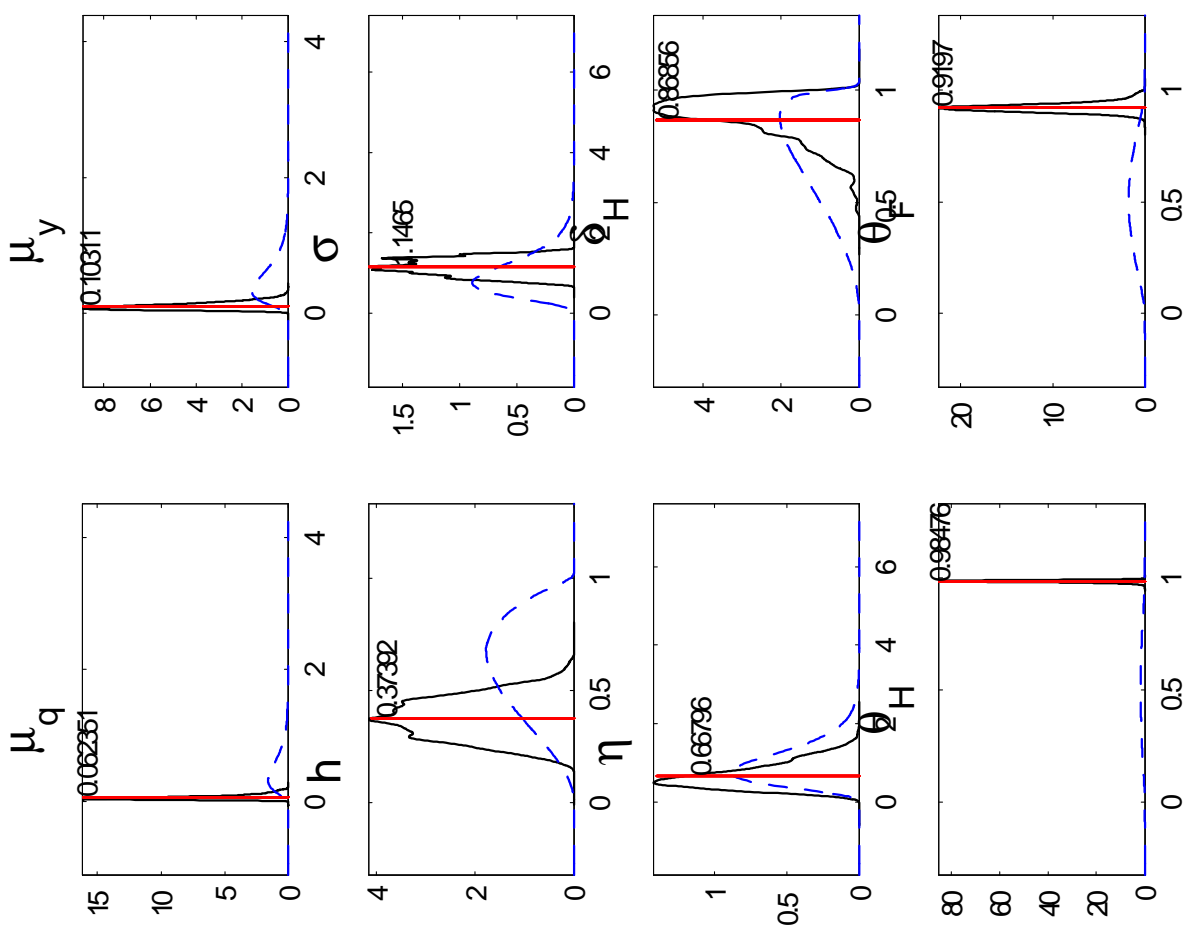

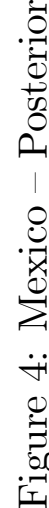



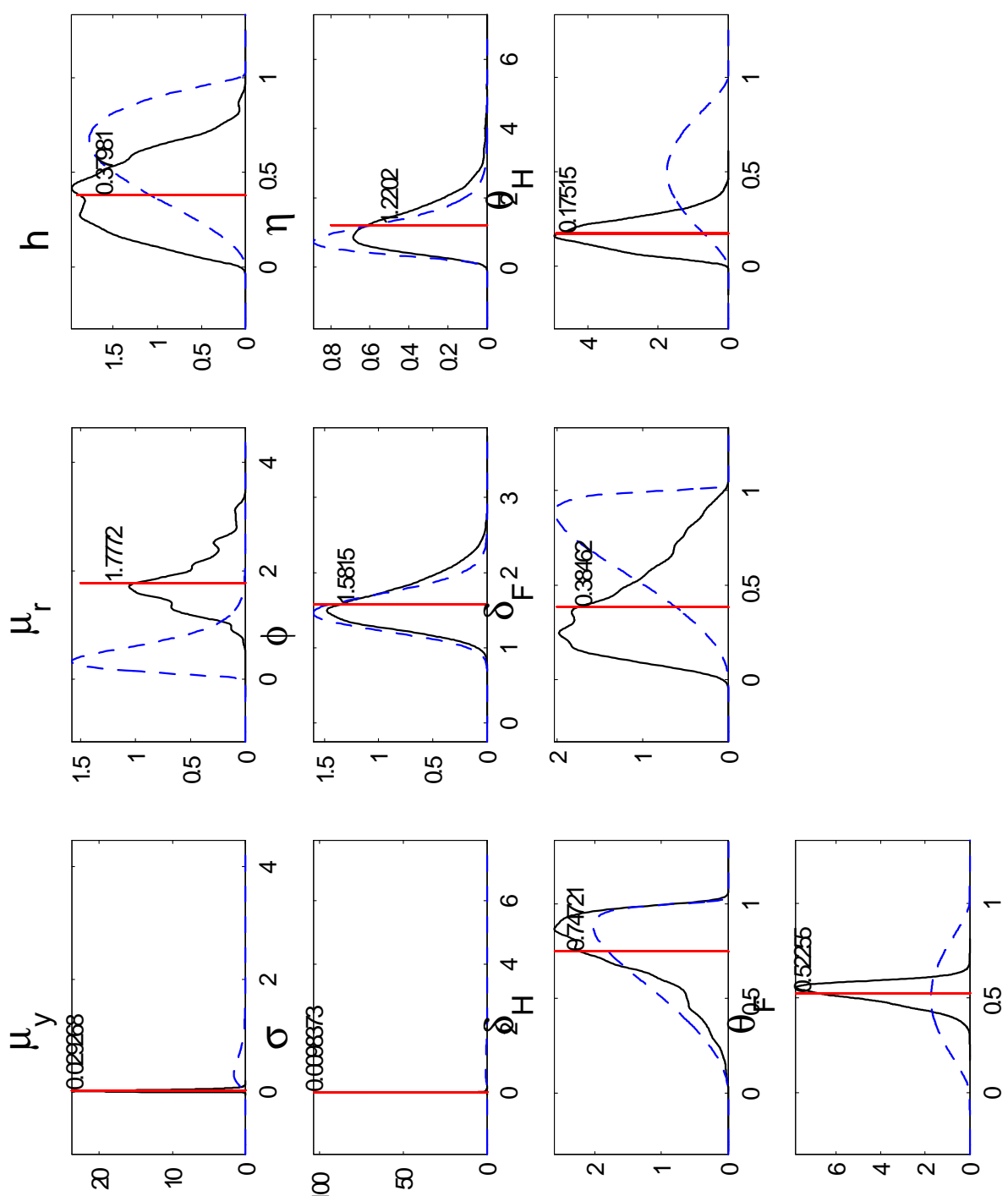


\begin{tabular}{cccccc}
\hline \hline Country & $\begin{array}{c}\text { Exchange Rate } \\
\text { Regime (2012) }\end{array}$ & $\begin{array}{c}\text { Year of IT } \\
\text { Adoption }\end{array}$ & $\begin{array}{c}\text { Annual Inflation } \\
\text { at IT Adoption }\end{array}$ & $\begin{array}{c}\text { Average Quarterly } \\
\text { Inlation since IT }\end{array}$ & $\begin{array}{c}\text { Inflation } \\
\text { Target }(2012)\end{array}$ \\
\hline Brazil & Floating & 1999 & 3.3 & 6.6 & $4.5 \pm 1$ \\
Chile & Free floating & 1999 & 3.2 & 3.2 & $3 \pm 1$ \\
Colombia & Floating & 1999 & 9.3 & 5.1 & $2-4$ \\
Guatemala & Stabilized arrangement & 2005 & 9.2 & 5.4 & $5 \pm 1$ \\
Mexico & Free floating & 2001 & 9.0 & 4.3 & $3 \pm 1$ \\
Peru & Floating & 2002 & -0.1 & 2.9 & $2 \pm 1$ \\
\hline \hline
\end{tabular}

Note: Annual inflation is expressed in \% per annum. Average quarterly inflation is computed from the first quarter of the year following IT adoption through the last quarter of 2014, and is expressed as $\%$ per annum. The exchange-rate regime classification is taken from IMF (2012). The inflation target is extracted from Jahan (2012).

Table 1: The 6 Latin American Inflation Targeters - Some Basic Facts 


\begin{tabular}{|c|c|c|c|c|}
\hline Parameters & Description & Prior pdf & Prior Mean & Prior SD \\
\hline \multicolumn{5}{|c|}{ Structural Parameters } \\
\hline$h$ & degree of habit persistence & $\mathcal{B}$ & 0.6 & 0.2 \\
\hline$\sigma$ & inverse of elasticity of intertemporal substitution in consumption & $\Gamma$ & 1.0 & 0.5 \\
\hline$\phi$ & inverse of Frisch elasticity of intertemporal labor supply & $\Gamma$ & 1.5 & 0.25 \\
\hline$\eta$ & elasticity of substitution between home and foreign goods & $\Gamma$ & 1.0 & 0.5 \\
\hline$\delta_{H}$ & degree of indexation in domestic-output markets & $\mathcal{B}$ & 0.7 & 0.2 \\
\hline$\delta_{F}$ & degree of indexation in imported-goods markets & $\mathcal{B}$ & 0.7 & 0.2 \\
\hline$\theta_{H}$ & degree of inflation persistence in domestic-output markets & $\mathcal{B}$ & 0.5 & 0.2 \\
\hline$\theta_{F}$ & degree of inflation persistence in imported-goods markets & $\mathcal{B}$ & 0.5 & 0.2 \\
\hline$a_{1}$ & degree of persistence in foreign inflation & $\mathcal{B}$ & 0.5 & 0.2 \\
\hline$b_{2}$ & degree of persistence in foreign output & $\mathcal{B}$ & 0.5 & 0.2 \\
\hline$c_{3}$ & degree of persistence in foreign interest rate & $\mathcal{B}$ & 0.5 & 0.2 \\
\hline$\rho_{a}$ & degree of persistence in technology shock & $\mathcal{B}$ & 0.5 & 0.2 \\
\hline$\rho_{q}$ & degree of persistence in risk premium shock & $\mathcal{B}$ & 0.9 & 0.2 \\
\hline$\rho_{s}$ & degree of persistence in terms of trade shock & $\mathcal{B}$ & 0.25 & 0.2 \\
\hline \multicolumn{5}{|c|}{ Relative Policy Target Weights } \\
\hline$\mu_{q}$ & real exchange rate stabilization & $\Gamma$ & 0.5 & 0.3 \\
\hline$\mu_{y}$ & output gap stabilization & $\Gamma$ & 0.5 & 0.3 \\
\hline$\mu_{r}$ & interest rate smoothing & $\Gamma$ & 0.5 & 0.3 \\
\hline \multicolumn{5}{|c|}{ Standard Deviation of Shock Innovations } \\
\hline$\sigma_{H}$ & domestic-output cost-push shock & Inverse $\Gamma$ & 0.5 & 0.25 \\
\hline$\sigma_{F}$ & imported-goods cost-push shock & Inverse $\Gamma$ & 0.5 & 0.25 \\
\hline$\sigma_{a}$ & technology shock & Inverse $\Gamma$ & 1.0 & 0.4 \\
\hline$\sigma_{q}$ & risk premium shock & Inverse $\Gamma$ & 2.0 & 0.5 \\
\hline$\sigma_{s}$ & terms of trade shock & Inverse $\Gamma$ & 1.0 & 0.4 \\
\hline$\sigma_{\pi^{*}}$ & foreign inflation shock & Inverse $\Gamma$ & 1.0 & 0.4 \\
\hline$\sigma_{y^{*}}$ & foreign output shock & Inverse $\Gamma$ & 1.0 & 0.4 \\
\hline$\sigma_{r^{*}}$ & foreign interest rate shock & Inverse $\Gamma$ & 1.0 & 0.4 \\
\hline$\sigma_{r}$ & interest rate shock & Inverse $\Gamma$ & 1.0 & 0.4 \\
\hline
\end{tabular}

Note: Parameters calibrated to a value common to all countries: $\beta=0.99 ; \chi=0.05$ (IAM). The parameter $\alpha$ is calibrated to a country-specific value. For the $\mu_{q}=0$ model specification, the prior and posterior distributions are degenerate at zero.

Table 2: Prior Distributions 


\begin{tabular}{llccc}
\hline \hline \multicolumn{2}{c}{ CAM } & \multicolumn{2}{l}{ IAM } \\
\hline & $\mu_{q}>0$ & $\mu_{q}=0$ & $\mu_{q}>0$ & $\mu_{q}=0$ \\
\hline Brazil & $\mathbf{- 1 4 3 1 . 5}$ & -1469.8 & -1502.7 & -1472.6 \\
Chile & $\mathbf{- 1 5 9 1 . 9}$ & -1606.4 & -1665.5 & -1771.5 \\
Colombia & $\mathbf{- 1 5 0 0 . 4}$ & -1506.2 & -1596.3 & -1584.4 \\
Mexico & $\mathbf{- 1 5 2 7 . 6}$ & -1560.7 & -1574.7 & -1592.5 \\
Peru & -1437.1 & $\mathbf{- 1 3 9 9 . 8}$ & -1523.1 & -3202.8 \\
\hline \hline
\end{tabular}

Note: The numbers report the marginal likelihood for each model version; the fonts in bold indicate the model version preferred by the data for each country.

Table 3: Bayesian Model Comparison - Complete versus Incomplete Asset Markets 


\begin{tabular}{|c|c|c|}
\hline & $\mu_{q}>0$ & $\mu_{q}=0$ \\
\hline \multicolumn{3}{|c|}{ Brazil (2004-2014) } \\
\hline Marginal Likelihood & -1431.5 & -1469.8 \\
\hline Acceptance Rate (\%) & 12.93 & 8.24 \\
\hline Indeterminacy Rate (\%) & 4.72 & 18.16 \\
\hline Invalid Likelihood Rate (\%) & 2.25 & 1.93 \\
\hline$\mu_{q}$ & $0.31(0.12)$ & 0 \\
\hline$\mu_{y}$ & $0.73(0.22)$ & $0.78(0.34)$ \\
\hline$\mu_{r}$ & $0.53(0.30)$ & $0.39(0.18)$ \\
\hline \multicolumn{3}{|c|}{ Chile (2002-2014) } \\
\hline Marginal Likelihood & -1591.9 & -1606.4 \\
\hline Acceptance Rate (\%) & 20.50 & 20.28 \\
\hline Indeterminacy Rate (\%) & 9.13 & 14.36 \\
\hline Invalid Likelihood Rate (\%) & 1.54 & 0.68 \\
\hline$\mu_{q}$ & $0.31(0.11)$ & 0 \\
\hline$\mu_{y}$ & $0.17(0.09)$ & $0.06(0.04)$ \\
\hline$\mu_{r}$ & $1.14(0.39)$ & $1.08(0.17)$ \\
\hline \multicolumn{3}{|c|}{ Colombia (2003-2014) } \\
\hline Marginal Likelihood & -1500.4 & -1506.2 \\
\hline Acceptance Rate (\%) & 16.80 & 18.61 \\
\hline Indeterminacy Rate (\%) & 5.41 & 6.31 \\
\hline Invalid Likelihood Rate (\%) & 1.78 & 1.90 \\
\hline$\mu_{q}$ & $0.10(0.06)$ & 0 \\
\hline$\mu_{y}$ & $0.44(0.16)$ & $0.37(0.15)$ \\
\hline$\mu_{r}$ & $0.35(0.24)$ & $0.43(0.23)$ \\
\hline \multicolumn{3}{|c|}{ Mexico (2002-2014) } \\
\hline Marginal Likelihood & -1527.6 & -1560.7 \\
\hline Acceptance Rate (\%) & 20.86 & 22.69 \\
\hline Indeterminacy Rate (\%) & 4.19 & 5.12 \\
\hline Invalid Likelihood Rate (\%) & 1.60 & 2.04 \\
\hline$\mu_{q}$ & $0.06(0.04)$ & 0 \\
\hline$\mu_{y}$ & $0.10(0.05)$ & $0.01(0.01)$ \\
\hline$\mu_{r}$ & $0.43(0.30)$ & $1.29(0.33)$ \\
\hline \multicolumn{3}{|c|}{ Peru (2005-2014) } \\
\hline Marginal Likelihood & -1437.1 & -1399.8 \\
\hline Acceptance Rate (\%) & 29.18 & 15.97 \\
\hline Indeterminacy Rate (\%) & 6.67 & 1.14 \\
\hline Invalid Likelihood Rate (\%) & 1.02 & 2.66 \\
\hline$\mu_{q}$ & $0.11(0.07)$ & 0 \\
\hline$\mu_{y}$ & $0.62(0.23)$ & $0.03(0.02)$ \\
\hline$\mu_{r}$ & $0.85(0.26)$ & $1.78(0.48)$ \\
\hline
\end{tabular}

Note: Estimates of the policy weights (relative to that of inflation, 1), $\mu_{i}$ with $i=\{q, y, r\}$, report the posterior mean, with the posterior standard deviation in parentheses.

Table 4: Bayesian Model Comparison - Complete Asset Markets 


\begin{tabular}{|c|c|c|}
\hline & $\mu_{q}>0$ & $\mu_{q}=0$ \\
\hline \multicolumn{3}{|c|}{ Brazil (2004-2014) } \\
\hline Marginal Likelihood & -1502.7 & -1472.6 \\
\hline Acceptance Rate (\%) & 16.35 & 11.74 \\
\hline Indeterminacy Rate (\%) & 29.83 & 6.13 \\
\hline Invalid Likelihood Rate (\%) & 0.00 & 0.03 \\
\hline$\mu_{q}$ & $0.02(0.01)$ & 0 \\
\hline$\mu_{y}$ & $0.17(0.06)$ & $0.11(0.07)$ \\
\hline$\mu_{r}$ & $0.88(0.08)$ & $0.31(0.13)$ \\
\hline \multicolumn{3}{|c|}{ Chile (2002-2014) } \\
\hline Marginal Likelihood & -1665.6 & -1771.5 \\
\hline Acceptance Rate (\%) & 0.26 & 20.00 \\
\hline Indeterminacy Rate (\%) & 42.06 & 23.78 \\
\hline Invalid Likelihood Rate (\%) & 0.00 & 0.00 \\
\hline$\mu_{q}$ & $0.03(0.02)$ & 0 \\
\hline$\mu_{y}$ & $0.83(0.05)$ & $0.83(0.12)$ \\
\hline$\mu_{r}$ & $0.81(0.07)$ & $0.63(0.07)$ \\
\hline \multicolumn{3}{|c|}{ Colombia (2003-2014) } \\
\hline Marginal Likelihood & -1596.3 & -1584.4 \\
\hline Acceptance Rate (\%) & 4.17 & 46.03 \\
\hline Indeterminacy Rate (\%) & 43.29 & 4.09 \\
\hline Invalid Likelihood Rate (\%) & 0.09 & 0.25 \\
\hline$\mu_{q}$ & $0.01(0.00)$ & 0 \\
\hline$\mu_{y}$ & $0.35(0.05)$ & $0.21(0.06) / 0.44(0.19)$ \\
\hline$\mu_{r}$ & $0.66(0.04)$ & $0.11(0.04) / 0.47(0.27)$ \\
\hline \multicolumn{3}{|c|}{ Mexico (2002-2014) } \\
\hline Marginal Likelihood & -1574.7 & -1592.5 \\
\hline Acceptance Rate (\%) & 30.86 & 27.65 \\
\hline Indeterminacy Rate (\%) & 1.95 & 3.48 \\
\hline Invalid Likelihood Rate (\%) & 0.76 & 0.10 \\
\hline$\mu_{q}$ & $0.37(0.23)$ & 0 \\
\hline$\mu_{y}$ & $0.50(0.28)$ & $0.10(0.06)$ \\
\hline$\mu_{r}$ & $0.54(0.22)$ & $0.57(0.26)$ \\
\hline \multicolumn{3}{|c|}{ Peru (2005-2014) } \\
\hline Marginal Likelihood & -1523.1 & -3202.8 \\
\hline Acceptance Rate (\%) & 8.02 & 2.58 \\
\hline Indeterminacy Rate (\%) & 33.07 & 93.03 \\
\hline Invalid Likelihood Rate (\%) & 0.00 & 0.00 \\
\hline$\mu_{q}$ & $0.04(0.02)$ & 0 \\
\hline$\mu_{y}$ & $0.22(0.13)$ & $0.06(0.01)$ \\
\hline$\mu_{r}$ & $0.63(0.18)$ & $0.33(0.01)$ \\
\hline
\end{tabular}

Note: Estimates of the policy weights (relative to that of inflation, 1), $\mu_{i}$ with $i=\{q, y, r\}$, report the posterior mean, with the posterior standard deviation in parentheses.

Table 5: Bayesian Model Comparison - Incomplete Asset Markets 


\begin{tabular}{|c|c|c|c|c|c|c|c|}
\hline Parameters & Post Mean & Post SD & $2.5 \%$ & $97.5 \%$ & NSE (8\%) & G p-value & B-GF \\
\hline \multicolumn{8}{|c|}{ Structural Parameters } \\
\hline$h$ & 0.30 & 0.10 & 0.19 & 0.93 & 0.01 & 0.53 & 1.00 \\
\hline$\sigma$ & 1.82 & 0.39 & 0.27 & 2.19 & 0.09 & 0.76 & 1.00 \\
\hline$\phi$ & 1.51 & 0.26 & 1.05 & 2.03 & 0.01 & 0.86 & 1.00 \\
\hline$\eta$ & 1.18 & 0.47 & 0.27 & 2.19 & 0.05 & 0.00 & 1.01 \\
\hline$\delta_{H}$ & 0.85 & 0.08 & 0.25 & 0.98 & 0.01 & 0.00 & 1.01 \\
\hline$\delta_{F}$ & 0.80 & 0.16 & 0.25 & 0.98 & 0.03 & 0.01 & 1.02 \\
\hline$\theta_{H}$ & 0.93 & 0.02 & 0.13 & 0.87 & 0.00 & 0.00 & 1.02 \\
\hline$\theta_{F}$ & 0.07 & 0.02 & 0.13 & 0.87 & 0.00 & 0.20 & 1.01 \\
\hline$a_{1}$ & 0.93 & 0.01 & 0.19 & 0.96 & 0.00 & 0.00 & 1.01 \\
\hline$b_{2}$ & 0.79 & 0.10 & 0.19 & 0.96 & 0.00 & 0.09 & 1.00 \\
\hline$c_{3}$ & 0.83 & 0.03 & 0.19 & 0.96 & 0.00 & 0.00 & 1.00 \\
\hline$\rho_{a}$ & 0.80 & 0.07 & 0.13 & 0.87 & 0.01 & 0.00 & 1.00 \\
\hline$\rho_{q}$ & 0.90 & 0.12 & 0.23 & 1.00 & 0.02 & 0.00 & 1.08 \\
\hline$\rho_{s}$ & 0.32 & 0.10 & 0.01 & 0.73 & 0.01 & 0.62 & 1.05 \\
\hline \multicolumn{8}{|c|}{ Relative Policy Target Weights } \\
\hline$\mu_{q}$ & 0.31 & 0.12 & 0.09 & 1.24 & 0.02 & 0.00 & 1.08 \\
\hline$\mu_{y}$ & 0.73 & 0.22 & 0.09 & 1.24 & 0.04 & 0.00 & 1.05 \\
\hline$\mu_{r}$ & 0.53 & 0.30 & 0.09 & 1.24 & 0.07 & 0.00 & 1.10 \\
\hline \multicolumn{8}{|c|}{ Standard Deviation of Shock Innovations } \\
\hline$\sigma_{H}$ & 10.38 & 2.92 & 0.91 & 7.34 & 0.75 & 0.00 & 1.02 \\
\hline$\sigma_{F}$ & 23.96 & 0.82 & 0.91 & 7.33 & 0.10 & 0.12 & 1.02 \\
\hline$\sigma_{a}$ & 1.89 & 0.59 & 0.52 & 2.66 & 0.07 & 0.96 & 1.03 \\
\hline$\sigma_{q}$ & 0.83 & 0.26 & 0.32 & 0.88 & 0.02 & 0.06 & 1.00 \\
\hline$\sigma_{s}$ & 15.33 & 1.43 & 0.52 & 2.66 & 0.33 & 0.00 & 1.02 \\
\hline$\sigma_{\pi^{*}}$ & 0.56 & 0.10 & 0.52 & 2.66 & 0.00 & 0.00 & 1.00 \\
\hline$\sigma_{y^{*}}$ & 0.72 & 0.11 & 0.52 & 2.66 & 0.00 & 0.00 & 1.00 \\
\hline$\sigma_{r^{*}}$ & 0.54 & 0.08 & 0.52 & 2.65 & 0.00 & 0.01 & 1.00 \\
\hline$\sigma_{r}$ & 0.40 & 0.12 & 0.52 & 2.67 & 0.01 & 0.00 & 1.00 \\
\hline
\end{tabular}

Note: Calibrated parameters: $\beta=0.99 ; \alpha=0.20$.

Table 6: Brazil, CAM - Posterior Parameters and Convergence Diagnostics $\left(\mu_{q}>0\right)$ 


\begin{tabular}{|c|c|c|c|c|c|c|c|}
\hline Parameters & Post Mean & Post SD & $2.5 \%$ & $97.5 \%$ & NSE (8\%) & G p-value & B-GF \\
\hline \multicolumn{8}{|c|}{ Structural Parameters } \\
\hline$h$ & 0.91 & 0.02 & 0.19 & 0.93 & 0.00 & 0.00 & 1.07 \\
\hline$\sigma$ & 0.20 & 0.05 & 0.27 & 2.20 & 0.01 & 0.00 & 1.20 \\
\hline$\phi$ & 1.87 & 0.22 & 1.05 & 2.03 & 0.02 & 0.00 & 1.06 \\
\hline$\eta$ & 0.11 & 0.04 & 0.27 & 2.19 & 0.00 & 0.00 & 1.00 \\
\hline$\delta_{H}^{\prime}$ & 0.39 & 0.07 & 0.25 & 0.98 & 0.01 & 0.04 & 1.03 \\
\hline$\delta_{F}$ & 0.27 & 0.07 & 0.25 & 0.98 & 0.01 & 0.89 & 1.01 \\
\hline$\theta_{H}$ & 0.60 & 0.03 & 0.13 & 0.87 & 0.00 & 0.00 & 1.06 \\
\hline$\theta_{F}$ & 0.61 & 0.03 & 0.13 & 0.87 & 0.00 & 0.00 & 1.02 \\
\hline$a_{1}$ & 0.98 & 0.00 & 0.19 & 0.96 & 0.00 & 0.34 & 1.02 \\
\hline$b_{2}$ & 0.75 & 0.09 & 0.19 & 0.96 & 0.00 & 0.00 & 1.01 \\
\hline$c_{3}$ & 0.89 & 0.03 & 0.19 & 0.96 & 0.00 & 0.01 & 1.04 \\
\hline$\rho_{a}$ & 0.27 & 0.14 & 0.13 & 0.87 & 0.03 & 0.00 & 1.11 \\
\hline$\rho_{q}$ & 0.88 & 0.14 & 0.24 & 1.00 & 0.04 & 0.00 & 1.48 \\
\hline$\rho_{s}$ & 0.72 & 0.08 & 0.01 & 0.72 & 0.01 & 0.04 & 1.01 \\
\hline \multicolumn{8}{|c|}{ Relative Policy Target Weights } \\
\hline$\mu_{q}$ & 0.31 & 0.11 & 0.09 & 1.24 & 0.03 & 0.00 & 1.07 \\
\hline$\mu_{y}$ & 0.17 & 0.09 & 0.09 & 1.24 & 0.02 & 0.00 & 1.03 \\
\hline$\mu_{r}$ & 1.14 & 0.39 & 0.09 & 1.24 & 0.11 & 0.68 & 1.69 \\
\hline \multicolumn{8}{|c|}{ Standard Deviation of Shock Innovations } \\
\hline$\sigma_{H}$ & 0.80 & 0.38 & 0.91 & 7.33 & 0.06 & 0.00 & 1.03 \\
\hline$\sigma_{F}$ & 9.27 & 0.83 & 0.91 & 7.36 & 0.19 & 0.00 & 1.04 \\
\hline$\sigma_{a}$ & 8.53 & 0.86 & 0.52 & 2.66 & 0.21 & 0.00 & 1.00 \\
\hline$\sigma_{q}$ & 0.79 & 0.18 & 0.32 & 0.87 & 0.01 & 0.01 & 1.01 \\
\hline$\sigma_{s}$ & 12.80 & 0.94 & 0.52 & 2.66 & 0.21 & 0.00 & 1.26 \\
\hline$\sigma_{\pi^{*}}$ & 0.22 & 0.03 & 0.52 & 2.66 & 0.00 & 0.52 & 1.00 \\
\hline$\sigma_{y^{*}}$ & 0.86 & 0.10 & 0.52 & 2.66 & 0.01 & 0.01 & 1.00 \\
\hline$\sigma_{r^{*}}$ & 0.20 & 0.02 & 0.52 & 2.65 & 0.00 & 0.98 & 1.00 \\
\hline$\sigma_{r}$ & 0.27 & 0.04 & 0.52 & 2.65 & 0.00 & 0.07 & 1.00 \\
\hline
\end{tabular}

Note: Calibrated parameters: $\beta=0.99 ; \alpha=0.51$.

Table 7: Chile, CAM - Posterior Parameters and Convergence Diagnostics $\left(\mu_{q}>0\right)$ 


\begin{tabular}{|c|c|c|c|c|c|c|c|}
\hline Parameters & Post Mean & Post SD & $2.5 \%$ & $97.5 \%$ & NSE (8\%) & G p-value & B-GF \\
\hline \multicolumn{8}{|c|}{ Structural Parameters } \\
\hline$h$ & 0.40 & 0.15 & 0.19 & 0.93 & 0.03 & 0.53 & 1.10 \\
\hline$\sigma$ & 1.77 & 0.52 & 0.27 & 2.19 & 0.13 & 0.01 & 1.09 \\
\hline$\phi$ & 1.49 & 0.25 & 1.05 & 2.03 & 0.01 & 0.78 & 1.00 \\
\hline$\eta$ & 0.79 & 0.28 & 0.27 & 2.19 & 0.02 & 0.08 & 1.00 \\
\hline$\delta_{H}$ & 0.77 & 0.08 & 0.25 & 0.98 & 0.01 & 0.00 & 1.06 \\
\hline$\delta_{F}$ & 0.14 & 0.08 & 0.25 & 0.98 & 0.01 & 0.01 & 1.01 \\
\hline$\theta_{H}$ & 0.95 & 0.01 & 0.13 & 0.87 & 0.00 & 0.76 & 1.00 \\
\hline$\theta_{F}$ & 0.31 & 0.05 & 0.13 & 0.87 & 0.01 & 0.00 & 1.02 \\
\hline$a_{1}$ & 0.94 & 0.01 & 0.19 & 0.96 & 0.00 & 0.35 & 1.00 \\
\hline$b_{2}$ & 0.75 & 0.11 & 0.19 & 0.96 & 0.00 & 0.83 & 1.00 \\
\hline$c_{3}$ & 0.83 & 0.03 & 0.19 & 0.96 & 0.00 & 0.55 & 1.00 \\
\hline$\rho_{a}$ & 0.60 & 0.10 & 0.13 & 0.87 & 0.01 & 0.02 & 1.00 \\
\hline$\rho_{q}$ & 0.86 & 0.23 & 0.23 & 1.00 & 0.05 & 0.01 & 1.13 \\
\hline$\rho_{s}$ & 0.21 & 0.08 & 0.01 & 0.72 & 0.01 & 0.03 & 1.02 \\
\hline \multicolumn{8}{|c|}{ Relative Policy Target Weights } \\
\hline$\mu_{q}$ & 0.10 & 0.06 & 0.09 & 1.24 & 0.01 & 0.01 & 1.00 \\
\hline$\mu_{y}$ & 0.44 & 0.16 & 0.09 & 1.24 & 0.02 & 0.01 & 1.03 \\
\hline$\mu_{r}$ & 0.35 & 0.24 & 0.09 & 1.24 & 0.05 & 0.00 & 1.03 \\
\hline \multicolumn{8}{|c|}{ Standard Deviation of Shock Innovations } \\
\hline$\sigma_{H}$ & 22.89 & 1.44 & 0.91 & 7.36 & 0.33 & 0.90 & 1.06 \\
\hline$\sigma_{F}$ & 24.22 & 0.61 & 0.91 & 7.37 & 0.10 & 0.00 & 1.09 \\
\hline$\sigma_{a}$ & 2.01 & 0.70 & 0.52 & 2.65 & 0.10 & 0.17 & 1.01 \\
\hline$\sigma_{q}$ & 0.67 & 0.16 & 0.32 & 0.88 & 0.01 & 0.28 & 1.00 \\
\hline$\sigma_{s}$ & 10.71 & 1.31 & 0.52 & 2.66 & 0.26 & 0.39 & 1.05 \\
\hline$\sigma_{\pi^{*}}$ & 0.37 & 0.06 & 0.52 & 2.66 & 0.00 & 0.02 & 1.01 \\
\hline$\sigma_{y^{*}}$ & 0.78 & 0.10 & 0.52 & 2.65 & 0.00 & 0.23 & 1.01 \\
\hline$\sigma_{r^{*}}$ & 0.53 & 0.07 & 0.52 & 2.65 & 0.00 & 0.36 & 1.00 \\
\hline$\sigma_{r}$ & 0.34 & 0.07 & 0.52 & 2.65 & 0.00 & 0.01 & 1.00 \\
\hline
\end{tabular}

Note: Calibrated parameters: $\beta=0.99 ; \alpha=0.29$.

Table 8: Colombia, CAM - Posterior Parameters and Convergence Diagnostics $\left(\mu_{q}>0\right)$ 


\begin{tabular}{|c|c|c|c|c|c|c|c|}
\hline Parameters & Post Mean & Post SD & $2.5 \%$ & $97.5 \%$ & NSE (8\%) & G p-value & B-GF \\
\hline \multicolumn{8}{|c|}{ Structural Parameters } \\
\hline$h$ & 0.37 & 0.09 & 0.19 & 0.93 & 0.01 & 0.47 & 1.00 \\
\hline$\sigma$ & 1.15 & 0.20 & 0.27 & 2.19 & 0.05 & 0.00 & 1.51 \\
\hline$\phi$ & 1.47 & 0.25 & 1.05 & 2.03 & 0.01 & 0.75 & 1.00 \\
\hline$\eta$ & 0.67 & 0.31 & 0.27 & 2.19 & 0.04 & 0.00 & 1.09 \\
\hline$\delta_{H}$ & 0.87 & 0.09 & 0.25 & 0.98 & 0.02 & 0.07 & 1.04 \\
\hline$\delta_{F}$ & 0.63 & 0.16 & 0.25 & 0.98 & 0.04 & 0.00 & 1.08 \\
\hline$\theta_{H}$ & 0.98 & 0.00 & 0.13 & 0.87 & 0.00 & 0.00 & 1.04 \\
\hline$\theta_{F}$ & 0.92 & 0.02 & 0.13 & 0.87 & 0.00 & 0.00 & 1.01 \\
\hline$a_{1}$ & 0.97 & 0.01 & 0.19 & 0.96 & 0.00 & 0.00 & 1.03 \\
\hline$b_{2}$ & 0.82 & 0.07 & 0.19 & 0.96 & 0.00 & 0.24 & 1.00 \\
\hline$c_{3}$ & 0.82 & 0.04 & 0.19 & 0.96 & 0.00 & 0.03 & 1.01 \\
\hline$\rho_{a}$ & 0.64 & 0.07 & 0.13 & 0.87 & 0.01 & 0.95 & 1.00 \\
\hline$\rho_{q}$ & 0.66 & 0.25 & 0.23 & 1.00 & 0.07 & 0.00 & 1.48 \\
\hline$\rho_{s}$ & 0.33 & 0.18 & 0.01 & 0.73 & 0.04 & 0.14 & 1.00 \\
\hline \multicolumn{8}{|c|}{ Relative Policy Target Weights } \\
\hline$\mu_{q}$ & 0.06 & 0.04 & 0.09 & 1.24 & 0.00 & 0.33 & 1.05 \\
\hline$\mu_{y}$ & 0.10 & 0.05 & 0.10 & 1.24 & 0.01 & 0.04 & 1.00 \\
\hline$\mu_{r}$ & 0.43 & 0.30 & 0.09 & 1.24 & 0.08 & 0.00 & 1.70 \\
\hline \multicolumn{8}{|c|}{ Standard Deviation of Shock Innovations } \\
\hline$\sigma_{H}$ & 22.95 & 1.19 & 0.91 & 7.31 & 0.31 & 0.59 & 1.25 \\
\hline$\sigma_{F}$ & 21.92 & 1.12 & 0.91 & 7.34 & 0.28 & 0.00 & 1.00 \\
\hline$\sigma_{a}$ & 14.28 & 0.82 & 0.52 & 2.66 & 0.19 & 0.01 & 1.02 \\
\hline$\sigma_{q}$ & 0.49 & 0.10 & 0.32 & 0.87 & 0.01 & 0.03 & 1.00 \\
\hline$\sigma_{s}$ & 0.39 & 0.11 & 0.52 & 2.65 & 0.01 & 0.94 & 1.01 \\
\hline$\sigma_{\pi^{*}}$ & 0.22 & 0.03 & 0.52 & 2.66 & 0.00 & 0.00 & 1.00 \\
\hline$\sigma_{y^{*}}$ & 0.62 & 0.07 & 0.52 & 2.65 & 0.00 & 0.93 & 1.00 \\
\hline$\sigma_{r^{*}}$ & 0.21 & 0.02 & 0.52 & 2.66 & 0.00 & 0.32 & 1.00 \\
\hline$\sigma_{r}$ & 0.37 & 0.06 & 0.52 & 2.66 & 0.01 & 0.44 & 1.01 \\
\hline
\end{tabular}

Note: Calibrated parameters: $\beta=0.99 ; \alpha=0.44$.

Table 9: Mexico, CAM - Posterior Parameters and Convergence Diagnos$\operatorname{tics}\left(\mu_{q}>0\right)$ 


\begin{tabular}{|c|c|c|c|c|c|c|c|}
\hline Parameters & Post Mean & Post SD & $2.5 \%$ & $97.5 \%$ & NSE (8\%) & "G p-value & $\overline{\mathrm{B}-\mathrm{GF}}$ \\
\hline \multicolumn{8}{|c|}{ Structural Parameters } \\
\hline$h$ & 0.38 & 0.18 & 0.19 & 0.93 & 0.02 & 0.03 & 1.00 \\
\hline$\sigma$ & 0.01 & 0.01 & 0.27 & 2.19 & 0.00 & 0.00 & 1.00 \\
\hline$\phi$ & 1.58 & 0.29 & 1.05 & 2.03 & 0.04 & 0.00 & 1.03 \\
\hline$\eta$ & 1.22 & 0.65 & 0.27 & 2.19 & 0.03 & 0.13 & 1.00 \\
\hline$\delta_{H}$ & 0.75 & 0.18 & 0.25 & 0.98 & 0.02 & 0.00 & 1.00 \\
\hline$\delta_{F}$ & 0.38 & 0.21 & 0.25 & 0.98 & 0.03 & 0.00 & 1.05 \\
\hline$\theta_{H}$ & 0.18 & 0.08 & 0.13 & 0.87 & 0.01 & 0.00 & 1.00 \\
\hline$\theta_{F}$ & 0.52 & 0.05 & 0.13 & 0.87 & 0.01 & 0.00 & 1.23 \\
\hline$a_{1}$ & 0.80 & 0.10 & 0.19 & 0.96 & 0.01 & 0.00 & 1.01 \\
\hline$b_{2}$ & 0.85 & 0.08 & 0.19 & 0.96 & 0.00 & 0.10 & 1.00 \\
\hline$c_{3}$ & 0.74 & 0.05 & 0.19 & 0.96 & 0.00 & 0.00 & 1.00 \\
\hline$\rho_{a}$ & 0.86 & 0.07 & 0.13 & 0.87 & 0.00 & 0.56 & 1.00 \\
\hline$\rho_{q}$ & 0.71 & 0.28 & 0.23 & 1.00 & 0.05 & 0.54 & 1.00 \\
\hline$\rho_{s}$ & 0.30 & 0.14 & 0.01 & 0.72 & 0.02 & 0.76 & 1.00 \\
\hline \multicolumn{8}{|c|}{ Relative Policy Target Weights } \\
\hline$\mu_{y}$ & 0.03 & 0.02 & 0.09 & 1.24 & 0.00 & 0.00 & 1.01 \\
\hline$\mu_{r}$ & 1.78 & 0.48 & 0.09 & 1.24 & 0.11 & 0.29 & 1.04 \\
\hline \multicolumn{8}{|c|}{ Standard Deviation of Shock Innovations } \\
\hline$\sigma_{H}$ & 3.28 & 0.96 & 0.91 & 7.32 & 0.18 & 0.00 & 1.06 \\
\hline$\sigma_{F}$ & 11.03 & 2.46 & 0.91 & 7.33 & 0.55 & 0.00 & 1.00 \\
\hline$\sigma_{a}$ & 13.10 & 2.06 & 0.52 & 2.66 & 0.48 & 0.00 & 1.38 \\
\hline$\sigma_{q}$ & 18.96 & 2.95 & 0.32 & 0.87 & 0.71 & 0.06 & 1.19 \\
\hline$\sigma_{s}$ & 8.37 & 1.01 & 0.52 & 2.65 & 0.13 & 0.32 & 1.00 \\
\hline$\sigma_{\pi^{*}}$ & 0.30 & 0.05 & 0.52 & 2.65 & 0.00 & 0.00 & 1.00 \\
\hline$\sigma_{y^{*}}$ & 0.59 & 0.09 & 0.52 & 2.66 & 0.00 & 0.00 & 1.00 \\
\hline$\sigma_{r^{*}}$ & 0.25 & 0.03 & 0.52 & 2.67 & 0.00 & 0.00 & 1.00 \\
\hline$\sigma_{r}$ & 0.42 & 0.13 & 0.52 & 2.66 & 0.02 & 0.00 & 1.01 \\
\hline
\end{tabular}

Note: Calibrated parameters: $\beta=0.99 ; \alpha=0.35$.

Table 10: Peru, CAM - Posterior Parameters and Convergence Diagnostics $\left(\mu_{q}=0\right)$ 